UNIVERSIDADE DE SÃO PAULO

FACULDADE DE FILOSOFIA, CIÊNCIAS E LETRAS DE RIBEIRÃO PRETO DEPARTAMENTO DE PSICOLOGIA PROGRAMA DE PÓS-GRADUAÇÃO EM PSICOBIOLOGIA

Envolvimento de mecanismos dopaminérgicos na expressão do medo condicionado contextual em ratos

Kátia Alessandra de Souza Caetano

Dissertação de mestrado apresentada à Faculdade de Filosofia, Ciências e Letras de Ribeirão Preto - USP, como parte das exigências para obtenção do título de Mestre em Ciências. Área de Concentração: Psicobiologia

Ribeirão Preto 
UNIVERSIDADE DE SÃO PAULO

FACULDADE DE FILOSOFIA, CIÊNCIAS E LETRAS DE RIBEIRÃO PRETO DEPARTAMENTO DE PSICOLOGIA PROGRAMA DE PÓS-GRADUAÇÃO EM PSICOBIOLOGIA

\title{
Envolvimento de mecanismos dopaminérgicos na expressão do medo condicionado contextual em ratos
}

\author{
Kátia Alessandra de Souza Caetano
}

Dissertação de mestrado apresentada à Faculdade de Filosofia, Ciências e Letras de Ribeirão Preto - USP, como parte das exigências para obtenção do título de Mestre em Ciências. Área de Concentração: Psicobiologia

Orientador: Prof. Dr. Marcus Lira Brandão

Ribeirão Preto 
Autorizo a reprodução e divulgação total ou parcial deste trabalho, por qualquer meio convencional ou eletrônico, para fins de estudo e pesquisa, desde que citada a fonte.

\section{FICHA CATALOGRÁFICA}

\section{Caetano, Kátia Alessandra de Souza}

Envolvimento de mecanismos dopaminérgicos na expressão do medo condicionado contextual em ratos. Ribeirão Preto, 2012.

$$
57 \text { p.: il.; } 30 \mathrm{~cm}
$$

Dissertação apresentada à Faculdade de Filosofia, Ciências e Letras de Ribeirão Preto da Universidade de São Paulo - Área de concentração: Psicobiologia.

Orientador: Marcus Lira Brandão.

1. Medo condicionado ao contexto. 2. Dopamina. 3. Área tegmental ventral. 4. Quimpirole. 5. Sulpirida. 6. Receptores dopaminérgicos. 7. Ansiedade. 


\section{AGRADECIMENTOS}

- Ao Prof. Dr. Marcus Lira Brandão, pela oportunidade dada de trabalhar e aprender em seu laboratório, pela confiança e orientação.

- À Dra. Amanda Ribeiro de Oliveira, que me ensinou muito mais do que a prática: ensinou-me o que é ser cientista e o que é dedicar-se a Ciência. Sem sua ajuda não teria chegado até aqui.

. À banca examinadora, pela atenção dispensada na leitura desta dissertação.

. Ao Me. Adriano Edgar Reimer, pelo auxílio com as fotomicrografias.

. À minha mãe Ilzete, pelo apoio incondicional, pelo exemplo de determinação e garra, e por estar presente nos momentos mais difíceis.

- Ao meu pai Paulo e à minha irmã Ana Paula, pela força, apoio e carinho sempre presentes.

. Ao Vanis, pelo companheirismo, apoio e por estar presente em minha vida.

. Aos meus amigos: Carol Castro, Débora, Ludmilla, Pedro e Ulisses. Cada um, à sua forma, contribuiu em tornar meus dias mais bonitos e minha vida melhor.

- Aos amigos do laboratório, pelo convívio e por terem tornado estes dois anos muito mais prazerosos.

- A todas as pessoas que direta ou indiretamente contribuíram para que chegasse até aqui e realizasse esse trabalho.

. A Deus, por todas as oportunidades dadas e por cuidar de minha vida.

. A CAPES e ao CNPq, pelo apoio financeiro.

Agradeço. 


\section{RESUMO}

É reconhecido que as experiências que geram reações de medo são praticamente indeléveis do encéfalo dos organismos e que condicionamentos aversivos suscitam inúmeras respostas defensivas, como o congelamento, sendo esta resposta um indicador de medo em roedores. Vários trabalhos têm apontado para a relação entre alterações na transmissão dopaminérgica e os estados aversivos. Entretanto, observam-se resultados conflitantes com a utilização de drogas dopaminérgicas em diferentes modelos animais de ansiedade. Assim, investigações devem ainda ser realizadas objetivando avaliar a funcionalidade da modulação dopaminérgica nos estados emocionais aversivos. O objetivo do presente estudo foi avaliar o envolvimento de mecanismos dopaminérgicos na expressão do medo condicionado ao contexto. Inicialmente foram avaliados os efeitos de agonistas (SKF 38393 e quimpirole) e antagonistas (SCH 23390 e sulpirida) de receptores D1 e D2 administrados sistemicamente sobre a expressão do medo condicionado contextual, sendo mensurado o tempo de congelamento dos animais. A atividade motora foi avaliada com o teste do campo aberto. Os resultados indicam que os receptores da família D2, e não D1, estão envolvidos na expressão do medo condicionado contextual, uma vez que a administração de quimpirole e sulpirida, mas não de SCH 23390 e SKF 38393, levou a uma diminuição do congelamento condicionado ao contexto. Não houve alterações na atividade motora dos animais. Com base nestes resultados foi levantada a hipótese de que a capacidade da sulpirida e do quimpirole em diminuir o medo condicionado poderia ocorrer devido a uma ação em receptores pós-sinápticos de estruturas do sistema mesocorticolímbico e em autoreceptores da área tegmental ventral (ATV), respectivamente, levando ao efeito comum de diminuição da atividade dopaminérgica. A fim de testar esta hipótese, foram realizadas microinjeções de quimpirole na ATV. Os resultados obtidos mostram uma diminuição da expressão do congelamento condicionado e que os efeitos obtidos com a administração sistêmica desse agonista de receptores D2 provavelmente devem-se a sua ação na ATV. Portanto, a ATV parece atuar na modulação das respostas de medo condicionado e a ativação desta estrutura deve ser importante para a recuperação da aprendizagem aversiva ocorrida no dia do condicionamento.

Palavras-chave: medo condicionado ao contexto; dopamina; área tegmental ventral; quimpirole; sulpirida; receptores dopaminérgicos; ansiedade. 


\begin{abstract}
It is well established that experiences that generate fear reactions are practically unforgettable and that aversive conditioning raises several defensive responses such as freezing, which is an index of fear in rodents. Several studies have pointed to the existence of a relationship between changes in dopaminergic neurotransmission and aversive states. However, there are conflicting results in the literature with the use of dopaminergic drugs in different animal models of anxiety. Thus, further investigations should be conducted to evaluate the importance of dopaminergic modulation of aversive states. The aim of the present study was to evaluate the involvement of dopaminergic neurotransmission in the expression of contextual conditioned fear in rats. Initially, we evaluated the effects of intraperitoneal injections of D1 and D2 receptors agonists (SKF 38393 and quinpirole) and antagonists (SCH 23390 and sulpiride) in the expression of contextual conditioned fear by measuring the time of freezing response of the animals. The motor activity was evaluated in the open field test. The results indicate that the D2 receptors, but not D1 receptors, are involved in the expression of contextual conditioned fear, since administration of quinpirole and sulpiride, but not SCH 23390 and SKF 38393, decreased conditioned freezing to the context. There were no changes in motor activity of animals. Based on these results it was hypothesized that quinpirole and sulpiride probably acted on presynaptic and postsynaptic D2 receptors, respectively, leading to a decrease of dopaminergic neurotransmission in both cases. To test this hypothesis, microinjections of quinpirole were performed into the ventral tegmental area (VTA). The results show a decrease in the expression of conditioned freezing, indicating that the effects obtained with the intraperitoneal administration of the dopamine D2 receptor agonist is probably due to its action in the VTA. Therefore, dopaminergic mechanisms in the VTA seem to be important in the modulation of conditioned fear responses and activation of this structure appears to take place during the fear memory following the context aversive conditioning.
\end{abstract}

Keywords: contextual conditioned fear; dopamine; ventral tegmental area; quinpirole; sulpiride; dopaminergic receptors; anxiety. 


\section{SUMÁRIO}

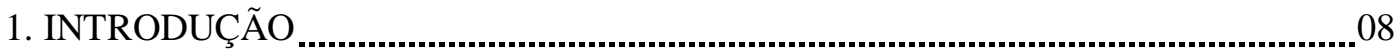

1.1. Congelamento condicionado ao contexto ..................................................10

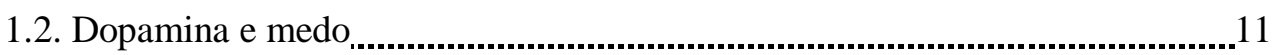

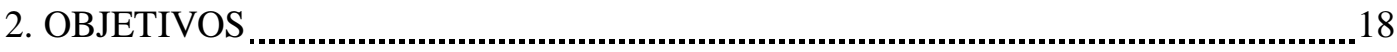

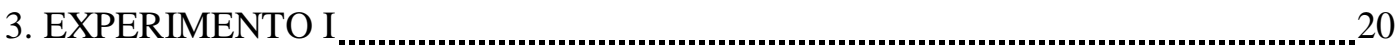

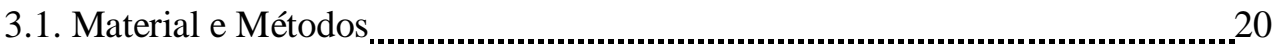

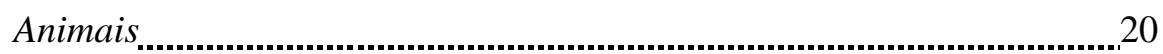

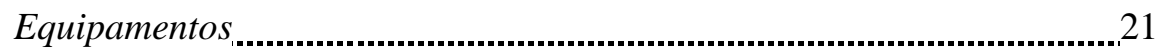

Procedimento Experimental .................................................................22

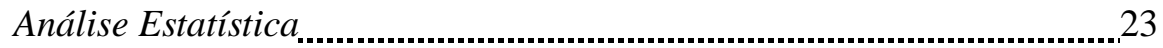

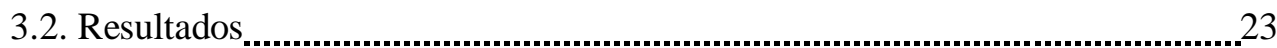

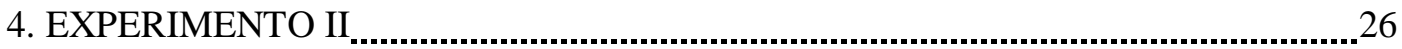

4.1. Material e Métodos ......................................................................................26

Animais

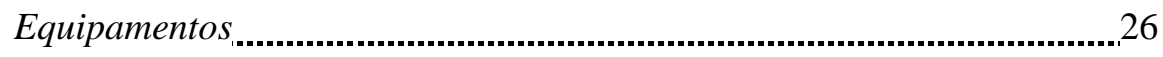

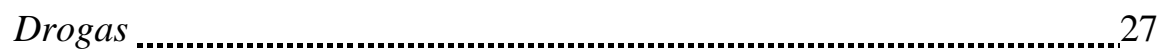

Procedimento Experimental ...........................................................2 28

Análise Estatística

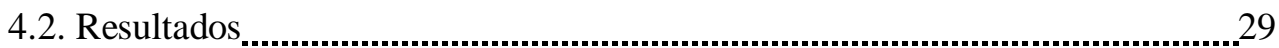

Receptores D1 na expressão do medo condicionado contextual........................29

Receptores D2 na expressão do medo condicionado contextual ...........................31

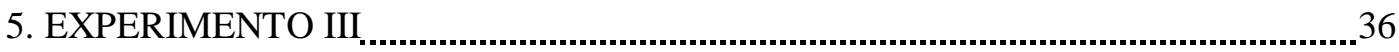

5.1. Material e Métodos ..................................................................................... 36

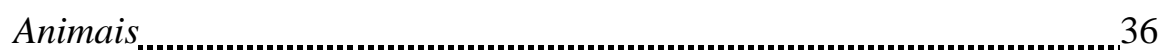

Equipamentos

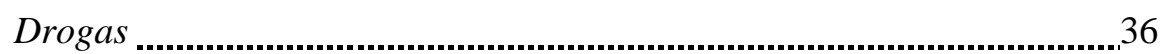

Procedimento Experimental ................................................................... 36

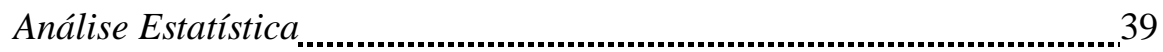

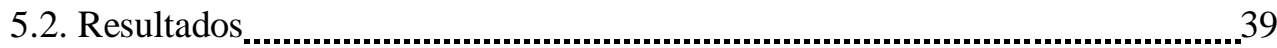

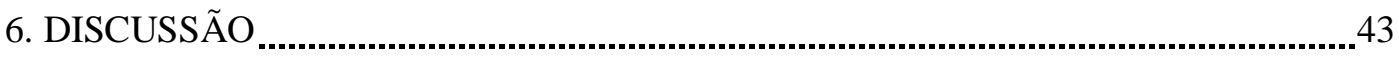

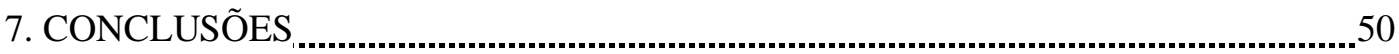

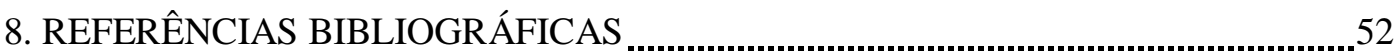


Introdução 


\section{INTRODUÇÃO}

É reconhecido que memórias emocionais de medo estão presentes na maioria das espécies animais, sendo que uma vez adquiridas, tornam-se praticamente indeléveis dos encéfalos dos organismos (LEDOUX, 2001). De uma perspectiva evolutiva, é extremamente importante que eventos que sinalizam perigo, seja esse potencial ou real, não sejam esquecidos, uma vez que preservam o indivíduo de um possível dano (KINDT et. al, 2009). Assim, medo e ansiedade são emoções adaptativas caracterizadas por um conjunto de alterações fisiológicas e comportamentais que ocorrem quando os indivíduos entram em contato com uma ameaça em seu ambiente (GROSS \& HEN, 2004; INDOVINA et. al, 2011). Entretanto, quando experenciados durante um longo período de tempo ou de forma excessiva, o medo e a ansiedade podem levar ao desenvolvimento de patologias, como ocorre nos transtornos de ansiedade, afetando significativamente a qualidade de vida do sujeito (GROSS \& HEN, 2004).

É possível observar que as respostas de defesa a situações aversivas são similares em diferentes espécies ao longo da escala evolutiva (DARWIN, 1872). Assim, essas respostas que foram preservadas ao longo da evolução são passíveis de serem estudadas em diversos animais, como em roedores, por exemplo. A compreensão dos componentes fisiológico e comportamental envolvidos nas respostas de defesa desses animais pode ser de grande utilidade para o entendimento dos comportamentos de medo em humanos e para o estabelecimento de terapêuticas mais eficazes para o tratamento dos distúrbios de ansiedade, como o Transtorno de Ansiedade Generalizada e o Transtorno do Pânico (BRANDÃO, 2004).

É vasta a literatura que discorre sobre as áreas e estruturas encefálicas ativadas quando um animal entra em contato com um estímulo aversivo e, em conseqüência, exibe comportamentos defensivos, como congelamento e fuga. Pesquisas realizadas nas décadas de 1970 e 1980 apontaram para a existência de um sistema encefálico de aversão acionado por estímulos de perigo e relacionado às respostas inatas de defesa. O hipotálamo medial, o 
complexo amigdalóide e a substância cinzenta periaquedutal dorsal (SCPd) são estruturas que compõem esse sistema, denominado Sistema Encefálico Aversivo (GRAEFF, 1981; GRAEFF, 1994). Pesquisas mais recentes têm incorporado outras estruturas mesencefálicas a esse sistema, como os colículos inferiores e superiores (para revisão ver BRANDÃO et al., 2003). Estudos utilizando a técnica de imunorreatividade da proteína Fos demonstram que as estruturas do sistema encefálico aversivo são marcadas após a exposição dos animais a uma estimulação ambiental aversiva, corroborando assim a hipótese de que tais estruturas compõem um sistema que é acionado por estímulos ameaçadores (SILVEIRA et al., 2001).

Foi também proposto outro sistema neural relacionado à estimulação aversiva, mas que está implicado, entretanto, com as reações condicionadas de medo e com a aprendizagem contextual aversiva. Esse sistema, denominado de Sistema de Inibição Comportamental, composto por estruturas como o septo e o hipocampo, atuaria suprimindo o comportamento operante mantido por recompensa ou estabelecendo respostas de esquiva, e responderia a estímulos aversivos condicionados, estímulos novos e frustração, possuindo o papel de detectar e avaliar o ambiente (GRAEFF, 1981; GRAY \& MCNAUGHTON, 2000). Assim, essas estruturas, especialmente o hipocampo, avaliam as informações contextuais, detectando conflitos entre informações já armazenadas e os estímulos provenientes do meio. Se uma incongruência é detectada, o hipocampo age aumentando a valência negativa da informação, e tornando-a mais ameaçadora do que realmente é. Ocorre assim, uma supressão das respostas do organismo e uma inibição comportamental (BRANDÃO, 2004).

Tanto a ativação do Sistema Encefálico Aversivo quanto do Sistema de Inibição Comportamental dependem da natureza do estímulo ao qual o organismo é exposto e do nível de ameaça que tal estímulo representa (BRANDÃO, 2004). Diferentes níveis de ameaça evocam distintos padrões de respostas defensivas, sendo que estímulos que sinalizam uma ameaça potencial, como um novo ambiente, levam a respostas de avaliação de risco, como uma exploração cautelosa do local. Já estímulos distais, como a percepção de um predador à 
determinada distância ou o reconhecimento de um contexto que foi previamente associado com um estímulo aversivo, como choque nas patas, evocam respostas de imobilidade com aumento da tensão e tônus muscular, como a resposta de congelamento condicionado contextual. Por fim, estímulos proximais, como o contato direto com o predador, levam a respostas do tipo fuga ou luta (BLANCHARD \& BLANCHARD, 1986).

\subsection{Congelamento condicionado ao contexto}

Condicionamentos aversivos que suscitam respostas de medo condicionadas, como o congelamento de um rato em um contexto onde anteriormente foram apresentados choques nas patas, levam a um aprendizado rápido, duradouro e cujas respostas emocionais são de difícil extinção. Nesse tipo de aprendizagem que ocorre devido a um condicionamento Pavloviano, um estímulo que a priori é emocionalmente neutro para o organismo, através de associações sucessivas com um estímulo incondicionado aversivo, torna-se um estímulo condicionado, sendo capaz de desencadear posteriormente e somente com sua apresentação, respostas de medo condicionadas, como o congelamento contextual (FENDT \& FANSELOW, 1999).

O congelamento é definido como a ausência total de movimentos do corpo e das vibrissas (exceto aqueles relacionados à respiração), acompanhado de alterações comportamentais e fisiológicas, como dorso arqueado, piloereção, exoftalmia, retração das orelhas, entre outras. Essa resposta é um indicador de medo nos animais, principalmente em ratos e camundongos. O congelamento possui alto valor adaptativo, pois a ausência de movimentos e o aumento da atenção, alerta e tonicidade muscular podem evitar um perigo potencial, haja vista que diminuem a probabilidade do animal ser percebido por seu predador (BOLLES \& COLLIER, 1976; FENDT \& FANSELOW, 1999).

O comportamento de congelamento é uma das respostas de defesa mais comuns em ratos expostos a estímulos aversivos (MISSLIN, 2003). Pesquisas atuais demonstram que existem, no mínimo, quatro tipos diferentes de congelamento, relacionados com substratos neurais e 
transtornos de ansiedade específicos: o congelamento condicionado e a imobilidade tônica, que estão relacionados aos substratos neurais de medo da parte ventral da substância cinzenta periaquedutal (SCPv); o congelamento evocado pela estimulação da SCPd; e o congelamento pós-estimulação da SCPd. Essas duas últimas condições estariam relacionadas aos ataques de pânico e ao Transtorno do Pânico, respectivamente, enquanto que o congelamento condicionado ao contexto, por exemplo, estaria relacionado ao Transtorno de Ansiedade Generalizada (BRANDÃO et al., 2008).

Evidências farmacológicas demonstram que apesar de todas essas respostas serem denominadas de congelamento, as mesmas guardam entre si diferenças importantes, haja vista que o mesmo fármaco possui distinto padrão de ação, conforme a resposta a ser avaliada. $\mathrm{O}$ congelamento condicionado, por exemplo, pode ser inibido com a administração do benzodiazepínico midazolam (SANTOS et al., 2005) enquanto que o congelamento evocado pela estimulação da SCPd é resistente à ação dessa classe de drogas, mostrando-se sensível, contudo, aos inibidores seletivos da recaptação de serotonina, como a fluoxetina (BORELLI et al., 2004).

\subsection{Dopamina e medo}

Observam-se na literatura inúmeros trabalhos que avaliaram as áreas encefálicas e circuitos neurais relacionados às respostas de medo. Entretanto, ainda não se encontra totalmente definido o papel dos diversos neurotransmissores nos estados aversivos, conhecimento que seria útil para uma melhor compreensão dos distúrbios de ansiedade e para o estabelecimento de terapêuticas mais eficazes para o tratamento de tais psicopatologias. Sabe-se que mecanismos serotoninérgicos (RUIZ-MARTINEZ et al., 2007; ZANOVELI et al., 2009); gabaérgicos (SANTOS et al., 2005; RUIZ-MARTINEZ et al., 2006; ZANOVELI \& BRANDÃO, 2008); dopaminérgicos (CARVALHO et al., 2009; CUADRA el al., 2000; DE OLIVEIRA et al., 2006; DE OLIVEIRA et al., 2009; GARCIA et al., 2005; REIS et al., 2004); entre outros, estão envolvidos na neurotransmissão dos estados emocionais de medo e ansiedade. 
Em relação à dopamina, está bem estabelecido na literatura que esse neurotransmissor atua como mediador de diferentes funções do sistema nervoso central dos mamíferos, como a regulação da atividade motora e de processos cognitivos, e principalmente a modulação das funções motivacionais relacionadas à recompensa (STUCHLIK et al., 2007). A fonte de inervação dopaminérgica no encéfalo de mamíferos encontra-se principalmente situada na região mesencefálica, com os corpos celulares dos neurônios dopaminérgicos agrupando-se principalmente na substância negra (grupo de neurônios A9) e dorsomedialmente a essa, na área tegmental ventral (ATV - grupo de neurônios A10). Da substância negra, partem eferentes que inervam principalmente o núcleo caudado e o putamen, formando a via mesoestriatal, sendo essa relacionada especialmente à motricidade. Já da ATV partem eferentes que inervam estruturas como o núcleo accumbens, hipocampo, amígdala, córtex cingulado e córtex pré-frontal, formando as vias mesolímbica e mesocortical, também denominadas de via mesocorticolímbica, sendo essa relacionada aos aspectos motivacionais do comportamento emocional e dos processos cognitivos (OADES \& HALLIDAY, 1987). É válido salientar que o feixe prosencefálico medial, conjunto de axônios que parte da ATV e que inerva estruturas pertencentes ao sistema mesocorticolímbico é também denominado de sistema cerebral de recompensa, uma vez que a estimulação deste feixe atua como reforçador de comportamentos operantes (OLDS \& MILNER, 1954).

Existem cinco tipos diferentes de receptores dopaminérgicos, que são agrupados em duas famílias: D1 (D1 e D5) e D2 (D2, D3 e D4). Os receptores da família D1 estão relacionados a uma proteína $\mathrm{G}$ estimulatória (Gs), à abertura de canais iônicos de Cálcio e a conseqüente despolarização da célula, levando à excitação neuronal e a propagação do impulso elétrico (CALLIER et al., 2003; MONSMA et al., 1990). Já os receptores da família D2 são considerados inibitórios, pois atuam hiperpolarizando o neurônio através de proteínas G inibitórias (Gi), e impedindo, consequentemente, a propagação do impulso (CALLIER et al., 2003; MONSMA et al., 1990). Os receptores dopaminérgicos podem ser classificados ainda como pré ou pós- 
sinápticos: os pré-sinápticos ou autoreceptores são sempre do tipo D2 (inibitórios) e atuam na regulação da liberação de dopamina para as células pós-sinápticas, sendo encontrados, em sua maioria, nos corpos celulares e dendritos da substância negra e da área tegmental ventral; já os receptores pós-sinápticos podem ser classificados como D1 ou D2. Pesquisas demonstram que os autoreceptores D2 são de 6 a 10 vezes mais sensíveis à ação de agonistas dopaminérgicos do que os receptores pós-sinápticos (SKIRBOLL et al., 1979). Estes últimos, portanto, são ativados com doses maiores de agonistas dopaminérgicos. Assim, dependendo da dose administrada, podem-se obter efeitos comportamentais opostos a partir da mesma droga utilizada, haja vista que o local de ação do fármaco pode ser um receptor pré ou pós-sináptico (MOORE \& BLOOM, 1978; SKIRBOLL et al., 1979).

Além das funções clássicas atribuídas à dopamina, pesquisas recentes têm demonstrado uma intensificação da neurotransmissão dopaminérgica nos estados de medo e ansiedade decorrentes de eventos estressores. Estudos demonstram que após o organismo ser exposto a estímulos aversivos ocorrem alterações na transmissão dopaminérgica: há um aumento na liberação de dopamina da ATV (DE OLIVEIRA et al., 2009; DE OLIVEIRA et al., 2011 ) para estruturas pertencentes ao sistema mesocorticolímbico (ABERCROMBIE et al., 1989; FEENSTRA et al., 1995). Essa relação entre dopamina e estados aversivos também é corroborada pelo aumento dos metabólitos desse neurotransmissor (ácido dihidroxifenilacético e ácido homovanílico) observados durante e após eventos estressores (ABERCROMBIE et al., 1989; D’ANGIO et al.,1988). É válido ressaltar ainda que frente a um estímulo condicionado aversivo, ocorre maior taxa de disparos de neurônios dopaminérgicos da ATV (GUARRACI \& KAPP, 1999); e que a injeção do agonista gabaérgico muscimol nesta estrutura leva a uma diminuição do medo condicionado (MUNRO \& KOKKINIDIS, 1997). Assim, a ATV pode ser mais um dos possíveis locais de ação de drogas ansiolíticas como os benzodiazepínicos, que ao incidir sobre esta estrutura levaria a uma diminuição da atividade dopaminérgica e, portanto, da 
expressão da associação aversiva adquirida no condicionamento, atenuando a saliência do estímulo condicionado (MUNRO \& KOKKINIDIS, 1997).

Entretanto, cabe destacar que não é toda a ATV que parece ser ativada por estímulos aversivos: estudos com registros eletrofisiológicos da atividade neuronial e com marcação imunoistoquímica demonstram que os neurônios dopaminérgicos da parte ventral da ATV são estimulados por eventos aversivos, sendo que os neurônios da parte dorsal são inibidos por este tipo de estimulação e ativados por reforçadores. Assim, parece que esta estrutura agrupa dois conjuntos de neurônios funcionalmente distintos, mas que de uma forma geral são ativados pela saliência ou propriedade dos estímulos: um que responde aos aspectos aversivos do ambiente e outro aos aspectos hedônicos dos estímulos (BRISCHOUX et al., 2009).

As principais estruturas do sistema mesocorticolímbico onde se observam aumento dos níveis de dopamina após a exposição do animal a eventos aversivos são o núcleo accumbens (RUIZ-MARTINEZ et. al, 2008); a amígdala (DE OLIVEIRA et. al, 2011) e o córtex pré-frontal (CPF) (ABERCROMBIE et al., 1989; CUADRA et. al, 2000; D'ANGIO et al.,1988, FEENSTRA et al., 1995). Entretanto, é válido ressaltar que essa resposta bioquímica que ocorre no CPF mediante uma situação aversiva, pode não ser um reflexo direto de um estado emocional de medo ou ansiedade, mas sim refletir maior atenção ou ativação de processos cognitivos em uma tentativa de lidar com o estímulo aversivo (D'ANGIO et al.,1988; SALUM et al., 2006).

As pesquisas mencionadas acima demonstram, portanto, a relação existente entre dopamina e eventos aversivos, sendo que se observa a ativação de mecanismos dopaminérgicos por vários tipos de estressores (D’ANGIO et al.,1988; PANI et al., 2000). Corroborando a hipótese de que a dopamina está associada com as propriedades aversivas dos estímulos está o fato de que a liberação deste neurotransmissor é inibida por ansiolíticos como o diazepam (FEENSTRA et al., 1995). Tais achados demonstram, portanto, que a dopamina está relacionada também à motivação aversiva, e não somente aos processos reforçadores positivos. 
Os efeitos da administração de agonistas e antagonistas dopaminérgicos, entretanto, dependem do modelo animal de ansiedade utilizado. Agonistas dopaminérgicos, como a apomorfina, aumentam de forma dose-dependente as respostas de esquiva condicionada no teste de esquiva de duas-vias; efeito contrário ocorre com os antagonistas dopaminérgicos SCH 23390 e sulpirida, que diminuem essa resposta de medo condicionado (CARVALHO et al., 2009; REIS et al., 2004). Já no teste de switch-off, que é considerado um teste de medo incondicionado, ocorre o efeito inverso: a apomorfina diminui, enquanto que a sulpirida aumenta as respostas de fuga à luz (REIS et al., 2004). Garcia e colaboradores (2005), por exemplo, demonstraram que a injeção sistêmica de apomorfina leva a um aumento do tempo gasto nos braços abertos e em suas extremidades no teste de labirinto em cruz elevado - outro teste de medo incondicionado agindo assim, supostamente como um composto com propriedade anti-aversiva. Os resultados aparentemente discrepantes encontrados na literatura obtidos com a utilização de agonistas e antagonistas dopaminérgicos nos diferentes modelos de ansiedade podem ser devidos ao tipo de situação aversiva a qual o organismo é exposto (sendo que diferentes estímulos condicionados ou incondicionados podem ativar estruturas e circuitos cerebrais distintos) e também, como mencionado anteriormente, devido à dose da droga utilizada, haja vista que o mesmo fármaco pode agir em receptores pré ou pós-sinápticos.

Está claro, portanto, que investigações devem ainda ser realizadas objetivando elucidar o papel que a dopamina e seus receptores possuem nos estados de medo e ansiedade. O presente estudo foi conduzido na sequiência de outros realizados nesse laboratório; como o de De Oliveira e colaboradores $(2006$; 2009), por exemplo, que ao realizarem administração do agonista D2 quimpirole tanto perifericamente, quanto em injeções pré-teste na ATV, observaram a diminuição da expressão do medo condicionado, utilizando a luz como estímulo condicionado.

Assim, como a literatura tem demonstrado que a ativação do circuito mesocorticolímbico através da neurotransmissão dopaminérgica é importante para a expressão de respostas defensivas frente a situações aversivas, a hipótese de trabalho levantada foi a de que a 
diminuição e a intensificação da neurotransmissão dopaminérgica através da utilização de antagonistas e agonistas dopaminérgicos levariam, respectivamente, a uma diminuição e aumento das respostas de medo condicionado. No presente estudo avaliamos o envolvimento de mecanismos dopaminérgicos na expressão do medo condicionado contextual. Para isso, utilizamos um procedimento de condicionamento aversivo no qual o contexto em que o animal se encontra (caixa experimental, um estímulo neutro) associado a apresentação de choques elétricos nas patas, torna-se um estímulo condicionado (sessão de condicionamento), desencadeando posteriormente e sem a apresentação dos choques, respostas de medo condicionado, como o congelamento contextual (sessão teste). 
Objetivos 


\section{OBJETIVOS}

Avaliar o envolvimento da neurotransmissão dopaminérgica na expressão do medo condicionado contextual em ratos. Foram avaliados os efeitos da administração sistêmica préteste de agonistas e antagonistas de receptores D1 e D2 sobre a resposta de congelamento condicionado ao contexto. Possíveis alterações no desempenho motor dos animais causadas pelas drogas foram avaliadas com o teste do campo aberto. Com base nos resultados obtidos foi avaliado também o envolvimento de receptores D2 da área tegmental ventral sobre a expressão do medo condicionado contextual, através da microinjeção bilateral do agonista D2 quimpirole nesta estrutura.

O estudo foi dividido em três fases:

- Experimento I: Padronização do teste de condicionamento contextual aversivo;

- Experimento II: Envolvimento de receptores D1 e D2 na expressão do medo condicionado ao contexto;

- Experimento III: Envolvimento de receptores D2 da área tegmental ventral na expressão do medo condicionado ao contexto. 
Experimento I:

Padronização do teste de condicionamento contextual aversivo 


\section{EXPERIMENTO I: PADRONIZAÇÃO DO TESTE DE CONDICIONAMENTO CONTEXTUAL AVERSIVO}

Este experimento objetivou demonstrar a validade do modelo experimental utilizado, ou seja, o estabelecimento de um condicionamento contextual. Inicialmente realizamos um experimento com um grupo de animais que não recebeu choques; um grupo que recebeu choques, mas que, entretanto, foi submetido à sessão teste em um contexto diferente da sessão de condicionamento; e um grupo que recebeu choques e que foi submetido à sessão teste no mesmo contexto da sessão de condicionamento. A resposta de congelamento foi avaliada durante o teste.

\subsection{Material e Métodos}

\section{Animais}

Foram utilizados 24 ratos Wistar machos com peso variando entre 250 e 300 g, provenientes do biotério central da Universidade de São Paulo (USP), campus Ribeirão Preto. Os animais foram agrupados em cinco sujeitos por caixa, em gaiolas de polipropileno $(30 \times 32 \times 18$ $\mathrm{cm}$ ) forradas com maravalha, tendo livre acesso à água e alimento. Os ratos foram mantidos em um biotério setorial com temperatura controlada de $23{ }^{\circ} \mathrm{C} \pm 1{ }^{\circ} \mathrm{C}$, sendo submetidos a um programa de iluminação artificial com ciclo claro-escuro $12 \times 12$ horas, com início do período claro às $7 \mathrm{~h}$. Todos os experimentos foram realizados durante a fase clara do ciclo. Os animais foram transportados individualmente até a sala experimental em uma caixa de polipropileno forrada com maravalha, medindo $28 \times 17 \times 13 \mathrm{~cm}$. Este trabalho faz parte de um Projeto Temático aprovado pela Comissão de Ética no Uso de Animais - CEUA - da USP - Ribeirão Preto (protocolo 06.1.123.8.53.9). 


\section{Equipamentos}

Caixas de medo condicionado: Foram utilizadas duas caixas experimentais distintas: a caixa Mesmo Contexto e a caixa Contexto Diferente (Fig. 1).

A caixa Mesmo Contexto (Fig. 1 - esquerda) mede $45 \times 26 \times 24 \mathrm{~cm}$, e possui as paredes laterais e do fundo construídas em acrílico preto. Já a porta, situada na face superior, e a parede frontal são de acrílico transparente. O piso da caixa é constituído por 36 grades eletrificadas de 5 mm de diâmetro cada, separadas $1 \mathrm{~cm}$ uma da outra e conectadas a um gerador de choques (Insight, SP, Brasil). O equipamento está contido em uma caixa $(64 \times 53 \times 48 \mathrm{~cm})$ de atenuação sonora feita de madeira, evitando assim a interferência de estímulos ambientais durante a execução dos procedimentos. Uma lâmpada incandescente vermelha disposta na parte superior da caixa permaneceu ligada durante os experimentos, permitindo assim a observação do animal pelo experimentador. Um odor de ácido acético (2\%) também foi utilizado para intensificar a caracterização do contexto. O odor advinha de um pequeno recipiente posicionado no piso da caixa de atenuação sonora, próximo à parede frontal da caixa de condicionamento. Esse estímulo foi utilizado nas sessões de condicionamento e teste somente na caixa Mesmo Contexto.

Já a caixa Contexto Diferente (Fig. 1 - direita) mede $25 \times 39 \times 25 \mathrm{~cm}$, sendo a parede do fundo e as laterais, assim como o piso, constituídos de acrílico transparente. Essa caixa também se encontra contida em uma câmara de atenuação acústica $(64 \times 53 \times 48 \mathrm{~cm})$ feita de madeira, com uma lâmpada incandescente vermelha que possibilita a observação dos animais. As paredes, piso e odor das caixas Mesmo Contexto e Contexto Diferente determinaram as diferenças contextuais entre os ambientes experimentais. 

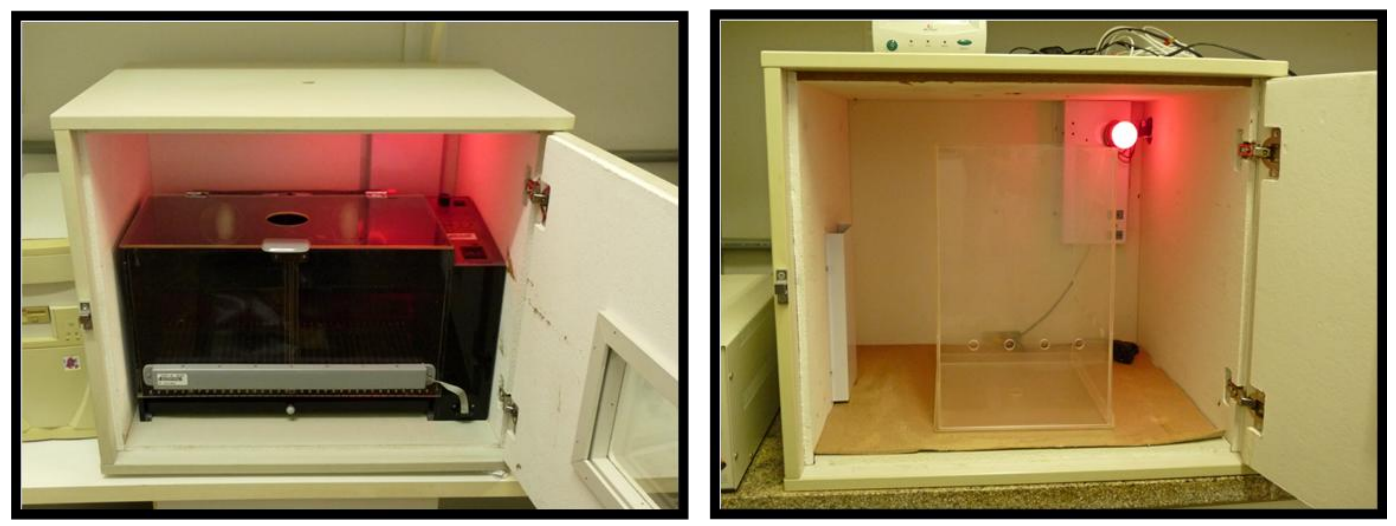

Fig. 1. Fotografias das caixas experimentais utilizadas para o procedimento de medo condicionado ao contexto. Esquerda - Mesmo Contexto. Direita - Contexto Diferente.

\section{Procedimento Experimental}

Medo condicionado ao contexto: $\mathrm{O}$ experimento de medo condicionado ao contexto foi dividido em duas sessões: a sessão de condicionamento e a sessão teste. Portanto, foram necessários dois dias consecutivos para a realização desse experimento.

Sessão de condicionamento: Nessa etapa os animais foram colocados na caixa Mesmo Contexto e, após 5 minutos de habituação, receberam 10 choques nas patas. Os choques tinham intensidade de 0,6 mA, com duração de 1 segundo cada, sendo variável o intervalo entre os choques (faixa de $30-90$ s), totalizando assim aproximadamente 10 minutos de distribuição desse estímulo aversivo incondicionado. O tempo total despendido nessa sessão foi de aproximadamente 15 minutos. Um grupo de animais denominado Sem Choque foi submetido ao mesmo protocolo experimental, sem, entretanto, receber choques nas patas.

Sessão teste: Após 24 horas, os animais foram colocados na caixa Mesmo Contexto ou Contexto Diferente, sendo que os animais do grupo Sem Choque foram colocados na caixa Mesmo Contexto. O tempo de congelamento foi registrado durante 10 minutos, sendo esse comportamento aqui definido como a ausência total de movimentos do corpo e das vibrissas (exceto aqueles relacionados à respiração) por um período mínimo de 6 segundos. 


\section{Análise Estatística}

Os dados são apresentados como média + EPM e foram analisados com o programa estatístico SigmaStat 3.11 (Systat Software Inc, Illinois, EUA). Para análise do tempo de congelamento no teste de medo condicionado ao contexto foi utilizada uma análise de variância (ANOVA) de uma via. No caso de significância estatística $(p<0,05)$, o teste de Newman-Keuls foi utilizado.

\subsection{Resultados}

Na figura 2 pode ser observado o tempo médio de congelamento dos grupos Sem Choque, Contexto Diferente e Mesmo Contexto. O tempo total de congelamento registrado na sessão teste foi submetido à ANOVA de uma via. A análise estatística revelou diferenças significativas entre os grupos $[\mathrm{F}(2,21)=8,11 ; p<0,05]$. O teste post hoc de Newman-Keuls revelou que o tempo médio de congelamento do grupo de animais submetido ao teste na mesma caixa onde ocorreu o condicionamento foi significativamente maior do que aquele do grupo que não recebeu choques e do grupo que recebeu choques, mas que, no entanto, foi submetido ao teste em um contexto diferente $(p<0,05)$. Não houve diferenças significativas entre o tempo de congelamento do grupo sem choque e contexto diferente $(p>0,05)$. 


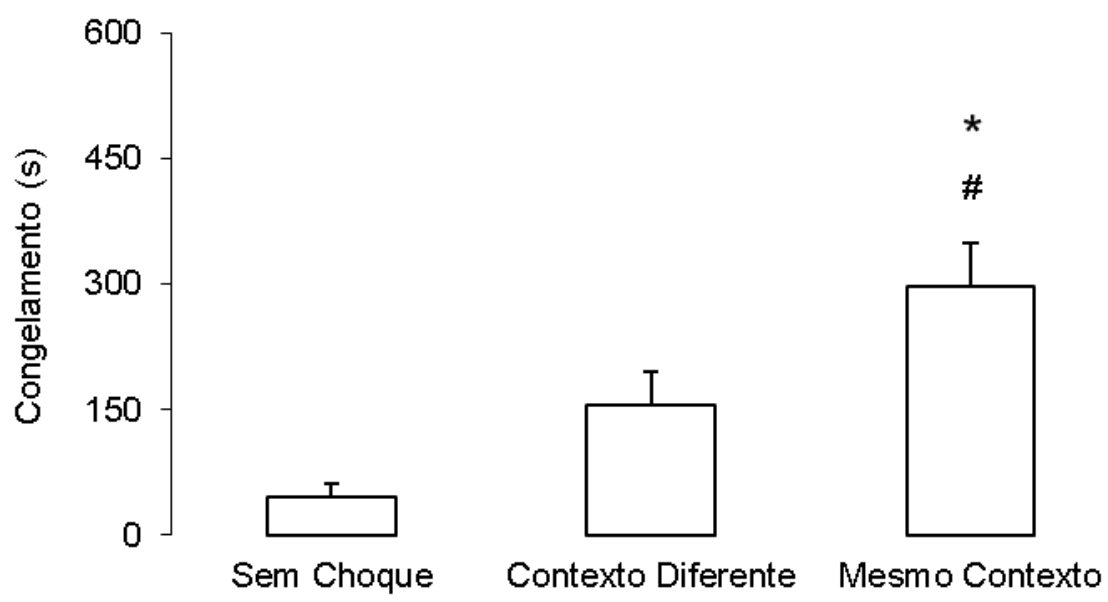

Fig. 2. Tempo médio de congelamento de animais submetidos ao procedimento de condicionamento ao contexto e testados no mesmo contexto ou em um contexto diferente. Os animais controle (sem choque) não receberam choques na sessão de condicionamento. ${ }^{*} p<0,05$ : diferente do grupo Sem Choque; \# $p<$ 0,05: diferente do grupo Contexto Diferente. Média + EPM. $n=6$ para o grupo Sem Choque; $n=9$ para os grupos Contexto Diferente e Mesmo Contexto. 
Experimento II:

Envolvimento de receptores D1 e D2 na expressão do medo condicionado ao contexto 


\section{EXPERIMENTO II: ENVOLVIMENTO DE RECEPTORES D1 E D2 NA EXPRESSÃO DO MEDO CONDICIONADO AO CONTEXTO}

Este experimento objetivou avaliar o envolvimento dos receptores dopaminérgicos D1 e D2 na expressão do medo condicionado contextual através da administração sistêmica de agonistas e antagonistas específicos.

\subsection{Material e Métodos}

\section{Animais}

Foram utilizados 116 ratos Wistar machos com peso variando entre 250 e $300 \mathrm{~g}$, mantidos sob as mesmas condições descritas para o Experimento I.

\section{Equipamentos}

Caixa de medo condicionado: Foi utilizada a caixa Mesmo Contexto, descrita no Experimento I.

Arena: Para avaliação do desempenho motor dos animais foi utilizada uma arena circular de acrílico transparente (60 $\mathrm{cm}$ de diâmetro e $50 \mathrm{~cm}$ de altura), colocada sobre um assoalho dividido em 12 quadrantes (Fig. 3). Os comportamentos emitidos pelos animais durante as sessões experimentais de 10 minutos de duração foram registrados em tempo real pelo observador e submetidos à posterior análise estatística. 


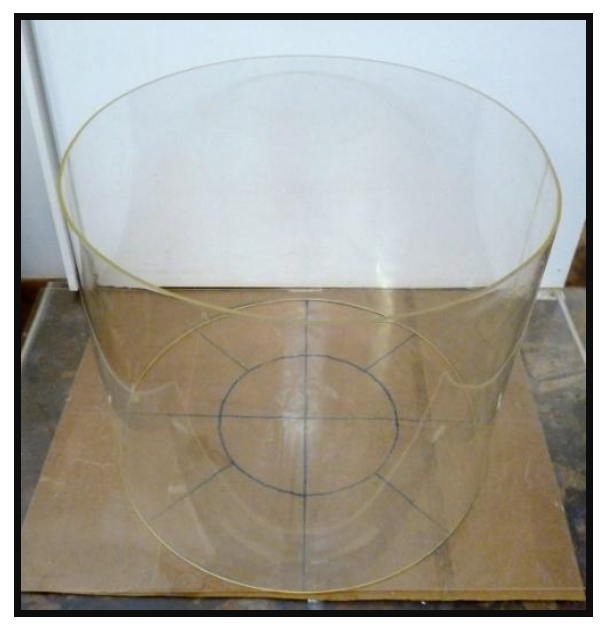

Fig. 3. Fotografia da arena utilizada para a avaliação da atividade motora.

\section{Drogas}

Foram utilizadas as seguintes drogas: o antagonista e o agonista de receptores da família D 1 SCH 23390 e SKF 38393, respectivamente; e o antagonista e o agonista de receptores da família $\mathrm{D}_{2}$, sulpirida e quimpirole, respectivamente. As drogas foram administradas em um volume constante de $1 \mathrm{~mL} / \mathrm{Kg}$. Quimpirole, SCH 23390 e SKF 38393 foram dissolvidos em salina fisiológica $(0,9 \%)$. Já a sulpirida foi primeiramente misturada a Tween 80 a 2\% (Sigma, MO, EUA) e, em seguida, dissolvida em salina fisiológica $(0,9 \%)$.

As drogas foram administradas intraperitonealmente 20 minutos (SKF 38393, sulpirida e quimpirole) ou 40 minutos (SCH 23390) antes da sessão teste. As doses utilizadas foram: 5 e 10 $\mathrm{mg} / \mathrm{Kg}$ para o SKF 38393; 0,025, 0,05 e 0,1 mg/Kg para o SCH 23390; 0,1 e 0,25 mg/Kg para o quimpirole; e 10, 20 e $40 \mathrm{mg} / \mathrm{Kg}$ para o sulpirida. As doses e o tempo de espera utilizados foram selecionados com base em estudos deste e de outros laboratórios (CARVALHO et al., 2009; DE OLIVEIRA et al., 2006; GARCIA et al., 2005; REIS et al., 2004; SALUM et al., 2006; STUCHLIK et al., 2007). 


\section{Procedimento Experimental}

Medo condicionado ao contexto: Este experimento foi dividido em duas sessões: a sessão de condicionamento e a sessão teste. Portanto, foram necessários dois dias consecutivos para a realização do experimento de medo condicionado ao contexto.

Sessão de condicionamento: Idêntica aquela descrita no Experimento I.

Sessão teste: Após 24 horas, os animais receberam administração intraperitoneal (ip.) de agonistas (SKF 38393 e Quimpirole) e antagonistas (SCH 23390 e Sulpirida) dopaminérgicos e posteriormente foram colocados na caixa Mesmo Contexto, sendo registrado, durante 10 minutos, o tempo de congelamento dos animais.

Teste do campo aberto: Os efeitos da administração sistêmica das drogas dopaminérgicas sobre a atividade motora dos animais foram avaliados por meio do teste do campo aberto. Após 10 minutos de habituação na arena, os animais receberam injeção ip. de drogas dopaminérgicas ou salina e, transcorridos 20 minutos (SKF 38393, sulpirida e quimpirole) ou 40 minutos (SCH 38393), foram recolocados no equipamento para registro da atividade motora durante um período de 10 minutos. A análise comportamental foi realizada a cada minuto ao longo de toda a sessão, e consistiu nas medidas de cruzamentos (resposta de cruzar para um dos quadrantes da arena com as quatro patas), levantamentos (resposta de erguer-se sobre as duas patas traseiras, mantendo as duas dianteiras elevadas, com ou sem apoio na parede da arena) e autolimpeza (resposta de higienização da cabeça e/ou corpo, utilizando as patas dianteiras).

\section{Análise Estatística}

Os dados são apresentados como média + EPM e foram analisados com o programa estatístico SigmaStat 3.11 (Systat Software Inc, Illinois, EUA). Para análise do tempo de congelamento no teste de medo condicionado ao contexto foi utilizada uma análise de variância (ANOVA) de uma via. A mesma análise foi utilizada para avaliação das medidas de 
cruzamentos, levantamentos e autolimpeza no teste do campo aberto. No caso de significância estatística $(p<0,05)$, o teste de Newman-Keuls foi utilizado.

\subsection{Resultados}

\section{Receptores D1 na expressão do medo condicionado contextual}

Na figura 4 podem ser observados os efeitos do tratamento com o antagonista D1 SCH 23390 sobre a expressão do medo condicionado contextual dos animais. A ANOVA de uma via não revelou diferenças significativas entre os grupos $[\mathrm{F}(3,29)=1,48 ; p>0,05]$.

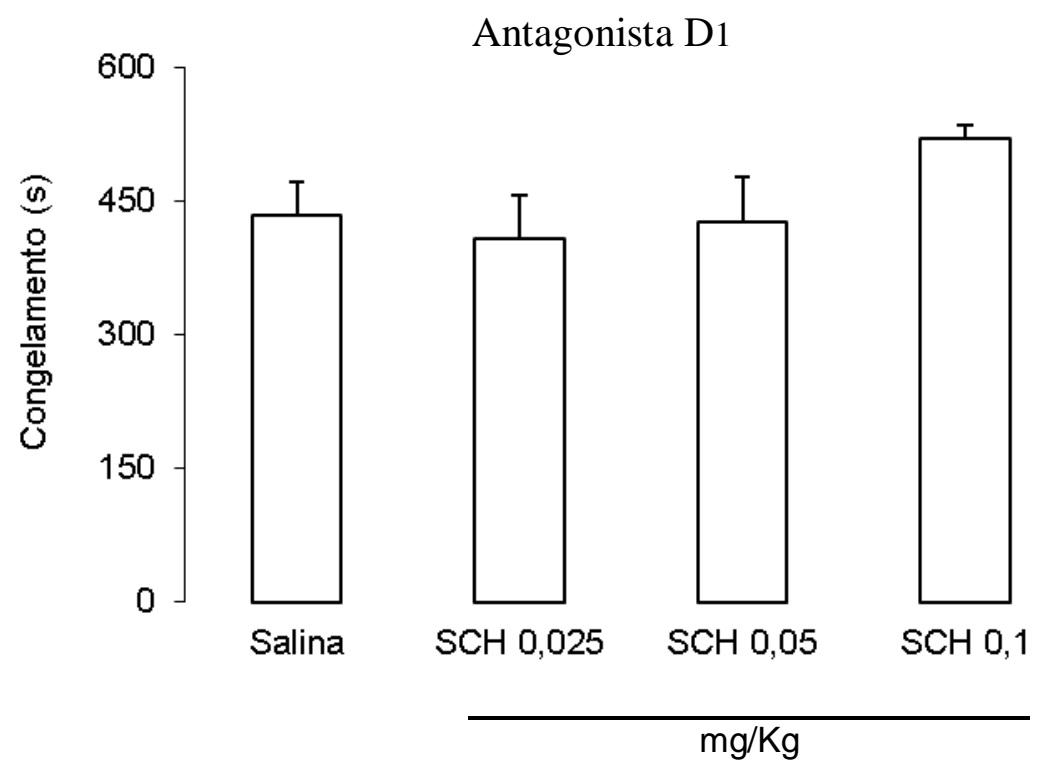

Fig. 4. Efeitos do tratamento ip. com salina ou SCH 23390 nas doses de 0,025 mg/Kg (SCH 0,025); 0,05 $\mathrm{mg} / \mathrm{Kg}(\mathrm{SCH} 0,05)$ e $0,1 \mathrm{mg} / \mathrm{Kg}$ (SCH 0,1) sobre o tempo médio de congelamento de animais submetidos ao procedimento de condicionamento ao contexto. Média + EPM. $n=9$ para SCH 0,025; $n=8$ para demais grupos.

A figura 5 ilustra os efeitos do tratamento com o agonista D1 SKF 38393 antes da sessão teste sobre o congelamento condicionado contextual no teste de medo condicionado ao contexto. A ANOVA de uma via não revelou diferenças significativas entre os grupos $[\mathrm{F}(2,21)=2,04 ; p>$ $0,05]$. 


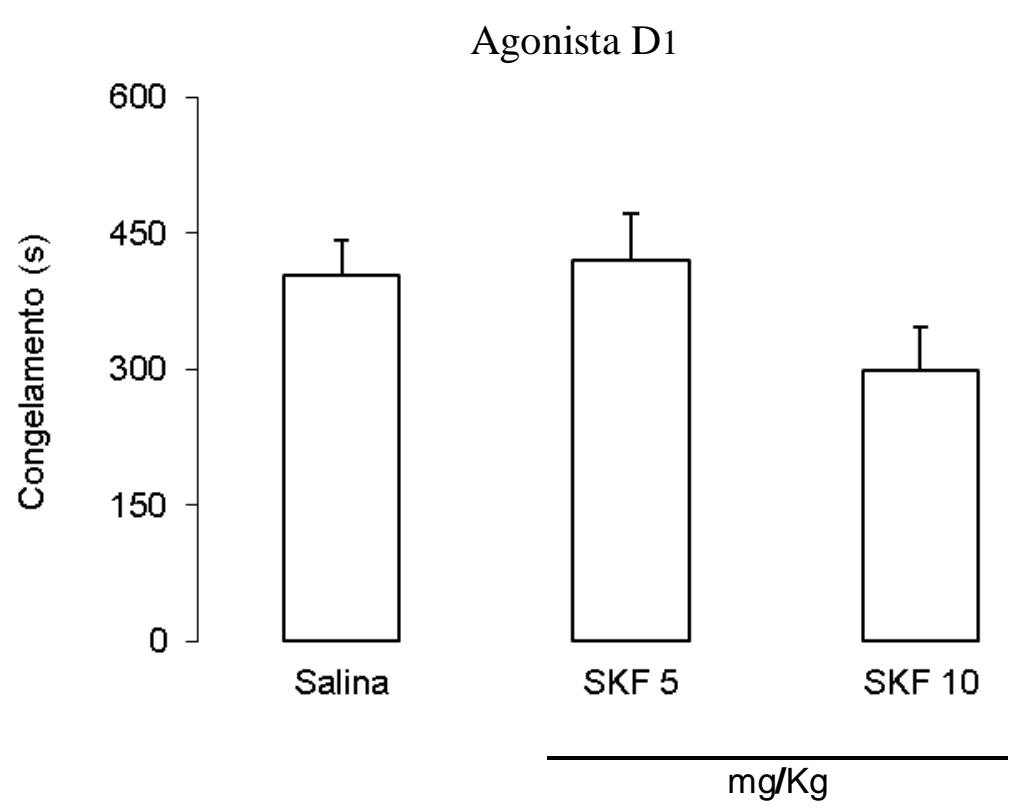

Fig. 5. Efeitos do tratamento ip. com salina ou SKF 38393 nas doses de $5 \mathrm{mg} / \mathrm{Kg}$ (SKF 5) e $10 \mathrm{mg} / \mathrm{Kg}$ (SKF 10) sobre o tempo médio de congelamento de animais submetidos ao procedimento de condicionamento ao contexto. Média + EPM. $\mathrm{n}=8$ para todos os grupos.

Para avaliar um eventual efeito das drogas dopaminérgicas de receptores da família D1 sobre a atividade motora dos animais, foi realizado o teste do campo aberto. A ANOVA de uma via aplicada aos cruzamentos revelou diferenças significativas entre os grupos $[\mathrm{F}(3,27)=10,57 ; p$ $<0,05]$, como pode ser observado na figura 6 (esquerda). $\mathrm{SCH} 23390$ na dose de $0,1 \mathrm{mg} / \mathrm{Kg}$ gerou alterações na atividade motora horizontal (cruzamentos) dos animais quando comparada com os grupos salina e SKF $3839310 \mathrm{mg} / \mathrm{Kg}(p<0,05)$. Existem ainda diferenças significativas entre os grupos SCH 23390 0,05 mg/Kg e SKF 3839310 mg/Kg ( $p<0,05$ ), que, entretanto não são observadas em relação ao grupo salina $(p>0,05)$. A ANOVA de uma via aplicada aos comportamentos de levantamento e autolimpeza também revelou diferenças significativas entre os grupos $[\mathrm{F}(3,27)=4,29 ; \mathrm{F}(3,27)=6,349$, respectivamente; $p<0,05]$, como pode ser observado na figura 6 (centro e direita, respectivamente). $\mathrm{SCH} 23390$ na dose de $0,1 \mathrm{mg} / \mathrm{Kg}$ diminuiu as respostas de levantamento e autolimpeza dos animais quando comparada com os demais grupos. 

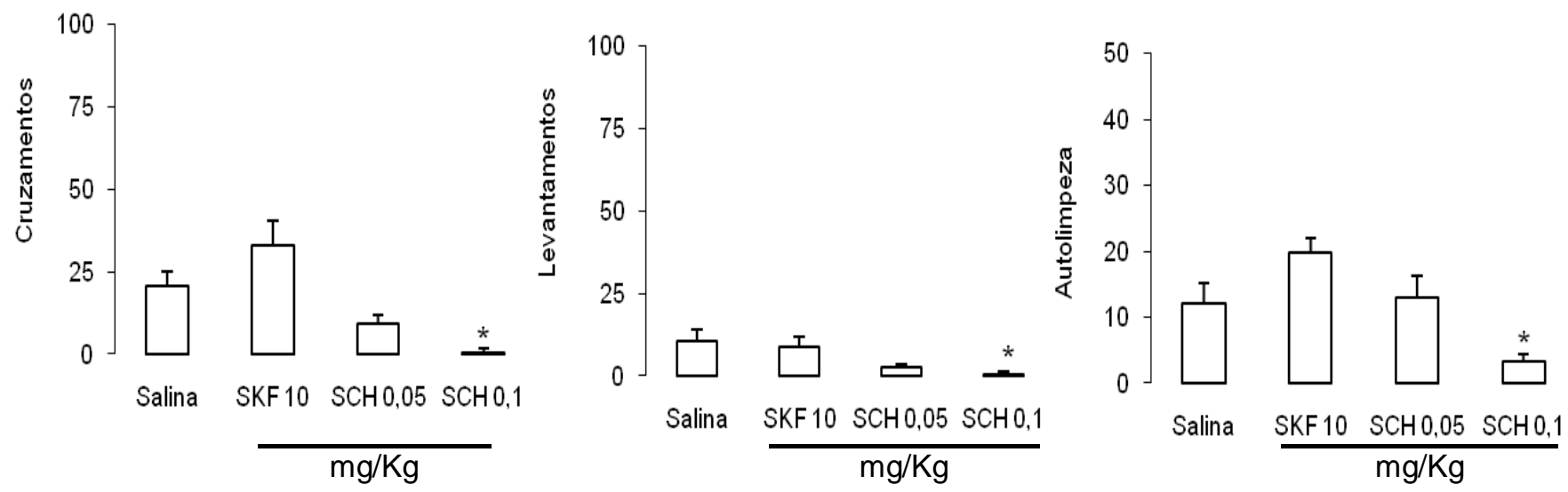

Fig. 6. Efeitos da injeção ip. de salina, SKF 3839310 mg/Kg (SKF 10), SCH 23390 0,05 mg/Kg (SCH 0,05) e SCH $23390 \quad 0,1 \mathrm{mg} / \mathrm{Kg}$ ( $\mathrm{SCH} 0,1$ ) sobre a atividade motora horizontal (cruzamentos), levantamentos e autolimpeza de animais submetidos ao teste do campo aberto. ${ }^{*} \mathrm{p}<0,05$ : diferente do grupo salina. Média + EPM. $n=9$ para Salina; $n=7$ para SKF 10 e SCH 0,05; e n = 8 para SCH 0,1.

\section{Receptores D2 na expressão do medo condicionado contextual}

A figura 7 ilustra os efeitos do tratamento com o antagonista D2 sulpirida antes da sessão teste sobre o tempo médio de congelamento dos animais no teste de medo condicionado ao contexto. A ANOVA de uma via revelou diferenças significativas entre os grupos $[\mathrm{F}(3,29)=4,87$; $p<0,05]$. O teste post hoc de Newman-Keuls revelou que sulpirida na maior dose $(40 \mathrm{mg} / \mathrm{Kg})$ reduziu o tempo médio de congelamento em relação aos grupos controle, sulpirida $10 \mathrm{mg} / \mathrm{Kg}$ e sulpirida $20 \mathrm{mg} / \mathrm{Kg}(p<0,05)$. 


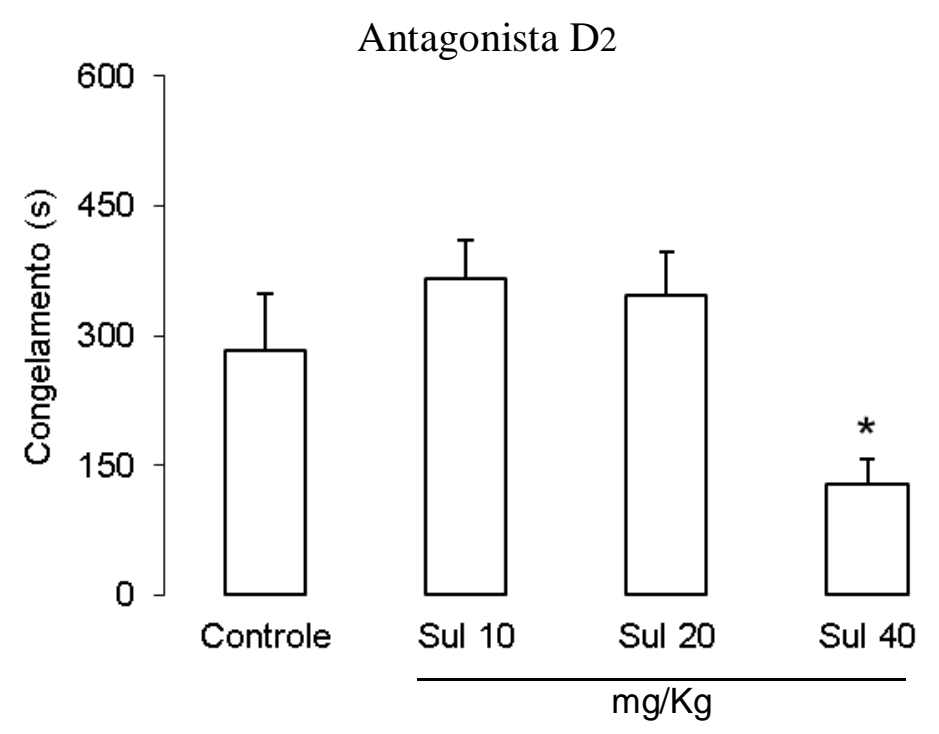

Fig. 7. Efeitos do tratamento ip. com sulpirida nas doses de $10 \mathrm{mg} / \mathrm{Kg}$ (Sul 10); $20 \mathrm{mg} / \mathrm{Kg}$ (Sul 20) e 40 $\mathrm{mg} / \mathrm{Kg}$ (Sul 40) sobre o tempo médio de congelamento de animais submetidos ao procedimento de condicionamento ao contexto em relação ao grupo controle (Controle: salina + tween 80 a 2\%-).* $p$ < 0,05: diferente do grupo salina. Média + EPM. $\mathrm{n}=9$ para o grupo Sul 10; $\mathrm{n}=8$ para demais grupos.

A figura 8 ilustra os efeitos do tratamento com o agonista D2 quimpirole no teste de medo condicionado ao contexto antes da sessão teste sobre o tempo médio de congelamento dos animais. A ANOVA de uma via revelou diferenças significativas entre os grupos $[\mathrm{F}(2,23)=$ 44,58; $\mathrm{p}<0,001]$. O teste post hoc de Newman-Keuls revelou que quimpirole, em ambas as doses administradas, foi eficaz em reduzir o tempo médio de congelamento dos animais em relação ao grupo salina $(p<0,05)$. 


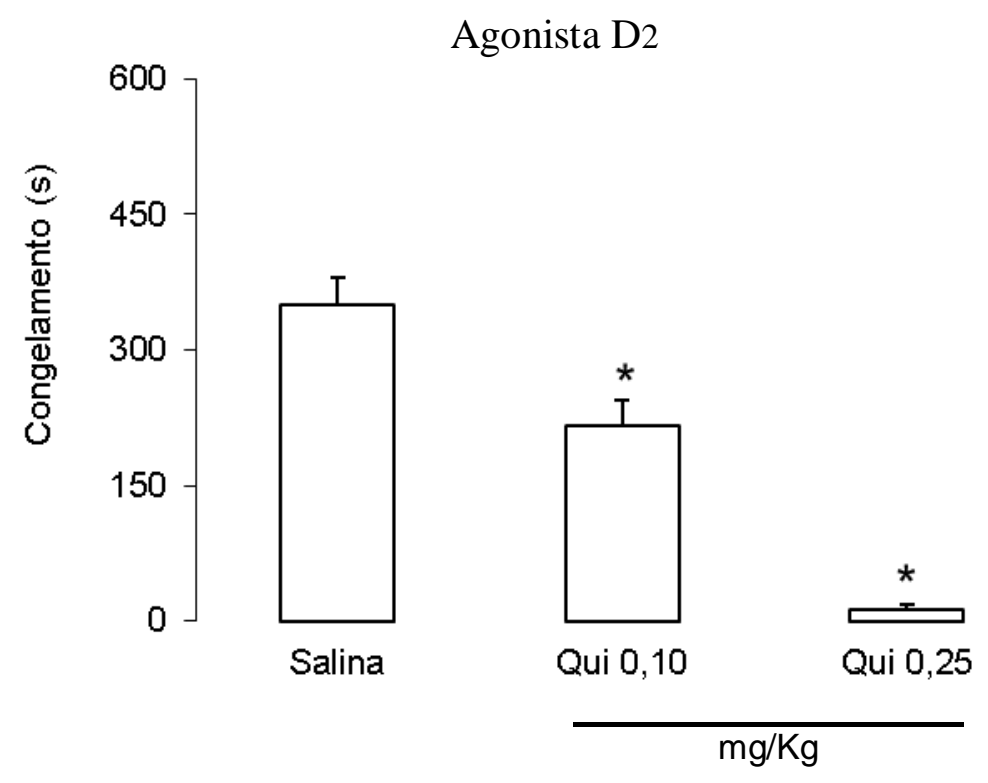

Fig. 8. Efeitos do tratamento ip. com salina ou quimpirole nas doses de $0,10 \mathrm{mg} / \mathrm{Kg}$ (Qui 0,10$)$ ou 0,25 $\mathrm{mg} / \mathrm{Kg}$ (Qui 0,25) sobre o tempo médio de congelamento de animais submetidos ao procedimento de condicionamento ao contexto. ${ }^{*} p<0,05$ : diferente do grupo salina. Média + EPM. $\mathrm{n}=9$ para os grupos salina e Qui 0,10; $\mathrm{n}=8$ para o grupo Qui 0,25.

Para avaliar um eventual efeito das drogas dopaminérgicas de receptores da família D2 sobre a atividade motora dos animais, foi realizado o teste do campo aberto. A ANOVA de uma via aplicada aos cruzamentos e levantamentos não revelou diferenças significativas entre os grupos $[\mathrm{F}(2,20)=1,33$ e 0,73 , respectivamente; $p>0,05]$, como pode ser observado na figura 9 (esquerda e centro, respectivamente). Já para o comportamento de autolimpeza, a ANOVA de uma via revelou diferenças significativas $[\mathrm{F}(2,20)=6,55 ; p<0,05]$. O teste post hoc de NewmanKeuls revelou diferenças entre os grupos sulpirida e quimpirole $(p<0,05)$. Entretanto, nenhuma significância estatística foi observada em relação ao grupo controle $(p>0,05)$, como pode ser observado na figura 9 (direita). 

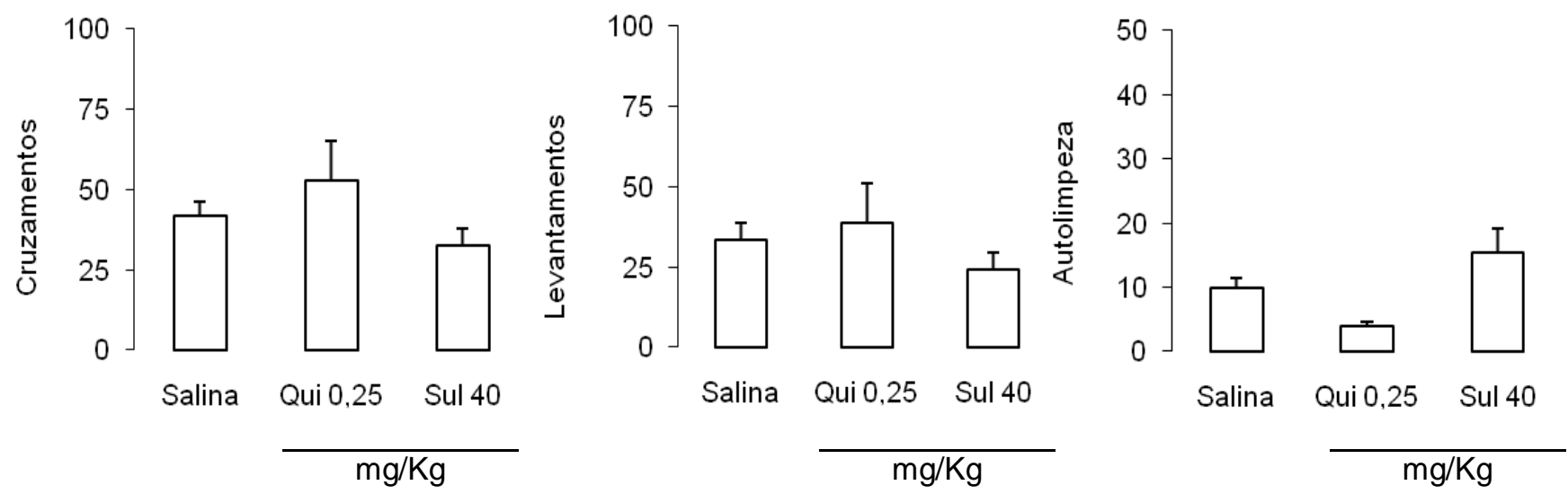

Fig. 9. Efeitos da injeção ip. de salina, quimpirole $0,25 \mathrm{mg} / \mathrm{Kg}$ (Qui 0,25) e sulpirida $40 \mathrm{mg} / \mathrm{Kg}$ (Sul 40) sobre a atividade motora horizontal (cruzamentos), levantamentos e autolimpeza de animais submetidos ao teste do campo aberto. Média + EPM. $n=8$ para Sal e Qui 0,25; $n=7$ para Sul 40. 
Experimento III:

Envolvimento de receptores D2 da ATV na expressão do medo condicionado 


\section{EXPERIMENTO III: ENVOLVIMENTO DE RECEPTORES D2 DA ÁREA TEGMENTAL VENTRAL NA EXPRESSÃO DO MEDO CONDICIONADO}

Este experimento objetivou avaliar o envolvimento dos receptores D2 da área tegmental ventral na expressão do medo condicionado contextual através da microinjeção bilateral de quimpirole nessa estrutura.

\subsection{Material e métodos}

\section{Animais}

Foram utilizados 31 ratos Wistar machos com peso variando entre 250 e 300 g, mantidos sob as mesmas condições descritas para o Experimento I.

\section{Equipamentos}

Caixa de medo condicionado: Foi utilizada a caixa Mesmo Contexto, descrita no Experimento I.

\section{Drogas}

Foi utilizado o agonista de receptores $\mathrm{D}_{2}$ quimpirole. A droga foi injetada bilateralmente na ATV na dose de $1,0 \mu \mathrm{g} / 0,2 \mu \mathrm{L}$ por sítio de microinjeção, quinze minutos antes do início da sessão teste. A dose e o tempo de espera foram selecionados com base em estudos deste laboratório, que mostraram que tal dose não gera alterações na atividade motora dos animais (DE OLIVEIRA et. al, 2009; DE OLIVEIRA et. al, 2011).

\section{Procedimento Experimental}


Cirurgia: Os animais foram pesados e posteriormente anestesiados por via intraperitoneal com Ketamina e Xilasina (100 e 7,5 mg/Kg respectivamente). Após a tricotomia do campo cirúrgico, tiveram o crânio fixado pelo rochedo temporal e incisivos superiores em um aparelho estereotáxico (David Kopf, CA, EUA). A barra dos incisivos foi ajustada a $3 \mathrm{~mm}$ abaixo da linha interaural. Posteriormente foi realizada a limpeza do campo cirúrgico com iodo a $1 \%$ em solução alcoólica e injetado subcutaneamente $0,2 \mathrm{~mL}$ de lidocaína 2\% (anestésico local; SS White, RJ, Brasil). Em seguida foi realizada uma incisão longitudinal, sendo removido o tecido subcutâneo e o periósteo (por raspagem, com auxílio de pinça e algodão). Assim, com a superfície craniana exposta, foram realizados dois orifícios nos ossos parietais com uma broca elétrica, sendo posteriormente fixados parafusos de aço inoxidável para ancoragem da prótese ao crânio do animal. Em seguida, outros dois orifícios foram feitos para implante das cânulas-guia (construídas a partir de agulhas comerciais de aço inoxidável de $0,7 \mathrm{~mm}$ de diâmetro externo e 14 mm de comprimento), que foram direcionadas à área tegmental ventral, utilizando para isto, as coordenadas do atlas de Paxinos e Watson (2007): ântero-posterior $=-5,9 \mathrm{~mm}$ do bregma, médio-lateral $= \pm 0,5 \mathrm{~mm}$ da sutura sagital, dorso-ventral $=-7,6 \mathrm{~mm}$ da superfície craniana. Após o implante das cânulas-guia o crânio foi revestido com acrílico dental (JET, SP, Brasil) possibilitando assim a fixação das cânulas, sendo que posteriormente estas foram seladas com fios de aço inoxidável para evitar uma possível obstrução. Ao término da cirurgia cada animal recebeu, por via intramuscular, uma injeção de $0,2 \mathrm{~mL}$ de um antibiótico veterinário de amplo espectro (Pentabiótico, 60.000 UI; Fort Dodge, SP, Brasil), e por via subcutânea uma injeção de 0,2 $\mathrm{mL}$ do antiinflamatório e analgésico flunixina meglumina (Banamine, $2,5 \mathrm{mg} / \mathrm{Kg}$; Schering Plough, RJ, Brasil), evitando assim, possíveis infecções e processos inflamatórios. Posteriormente os animais retornaram para suas gaiolas para um período de cinco dias de recuperação. 
Microinjeção de drogas: Durante este procedimento, que ocorreu 15 minutos antes da sessão teste, os animais foram colocados em uma caixa de polipropileno medindo $28 \times 17 \times 13$ $\mathrm{cm}$, forrada com maravalha. Um tubo de polietileno (PE -10; Beckton-Dickinson, NJ, EUA) foi conectado a uma agulha dental de $15 \mathrm{~mm}$ de comprimento e a uma seringa Hamilton graduada de $10 \mu \mathrm{L}$. A agulha dental, por sua vez, foi inserida na cânula-guia. A droga foi então bilateralmente injetada com o auxílio de uma bomba de infusão (Harvard Apparatus, MA, EUA) na ATV em um volume constante de $0,2 \mu \mathrm{L}$ e durante o período de 1 minuto. O deslocamento de uma bolha de ar no interior do tubo de polietileno foi utilizado para monitorar a microinjeção. Após o término da infusão, a agulha foi mantida por mais 1 minuto, evitando assim o refluxo da droga pela cânula-guia.

Medo condicionado ao contexto: Transcorrido o período de recuperação cirúrgica (cinco dias), os animais foram submetidos ao experimento de medo condicionado ao contexto, que foi dividido em duas sessões: a sessão de condicionamento e a sessão teste. Foram necessários, portanto, dois dias consecutivos para a realização deste experimento.

Sessão de condicionamento: Idêntica aquela descrita no Experimento I.

Sessão teste: Após 24 horas os animais foram submetidos ao procedimento de microinjeção de drogas descrito anteriormente e, transcorridos 15 minutos da infusão de quimpirole ou salina na ATV, foram colocados na caixa Mesmo Contexto, sendo registrado durante 10 minutos o tempo de congelamento dos animais.

Histologia: Após a realização do experimento de medo condicionado ao contexto, os animais foram anestesiados intraperitonealmente com uretana $(3 \mathrm{~g} / \mathrm{Kg}$; Sigma - Aldrich, MO, USA). Posteriormente, foram perfundidos por via intracardíaca com salina $0,9 \%$, seguida de formalina $4 \%$. Os encéfalos foram então removidos das caixas cranianas, mantidos em solução de formalina por 24 horas e, posteriormente, transferidos para uma solução de sacarose $30 \%$, 
onde permaneceram por 48 horas a $4^{\circ} \mathrm{C}$. Em seguida, os encéfalos foram congelados em um criostato e depois cortados em secções coronais de $60 \mu \mathrm{m}$. Lâminas previamente gelatinizadas foram utilizadas para a fixação dos cortes, sendo que posteriormente foram submetidas ao protocolo de coloração de Nissl, com a aplicação do corante violeta de cresila (5\%, Sigma), para que assim fosse viabilizada a observação dos sítios de microinjeções, de acordo com o Atlas de Paxinos e Watson (2007).

\section{Análise Estatística}

Os dados são apresentados como média + EPM e foram analisados com o programa estatístico SigmaStat 3.11 (Systat Software Inc, Illinois, EUA). Foi utilizada para avaliação do tempo de congelamento uma análise de variância (ANOVA) de uma via. No caso de significância estatística $(p<0,05)$, o teste de Newman-Keuls foi utilizado.

\subsection{Resultados}

A figura 10A mostra um corte histológico representativo da microinjeção na ATV. Os pontos de microinjeção cujas cânulas-guia atingiram bilateralmente a ATV foram representados em secções do mesencéfalo de ratos de acordo com o Atlas de Paxinos e Watson (2007) e são apresentadas na figura 10B. Em dez animais os sítios de injeção se localizaram em áreas vizinhas à ATV. Estes animais foram considerados na análise estatística e constituíram um grupo (Qui 1-). 

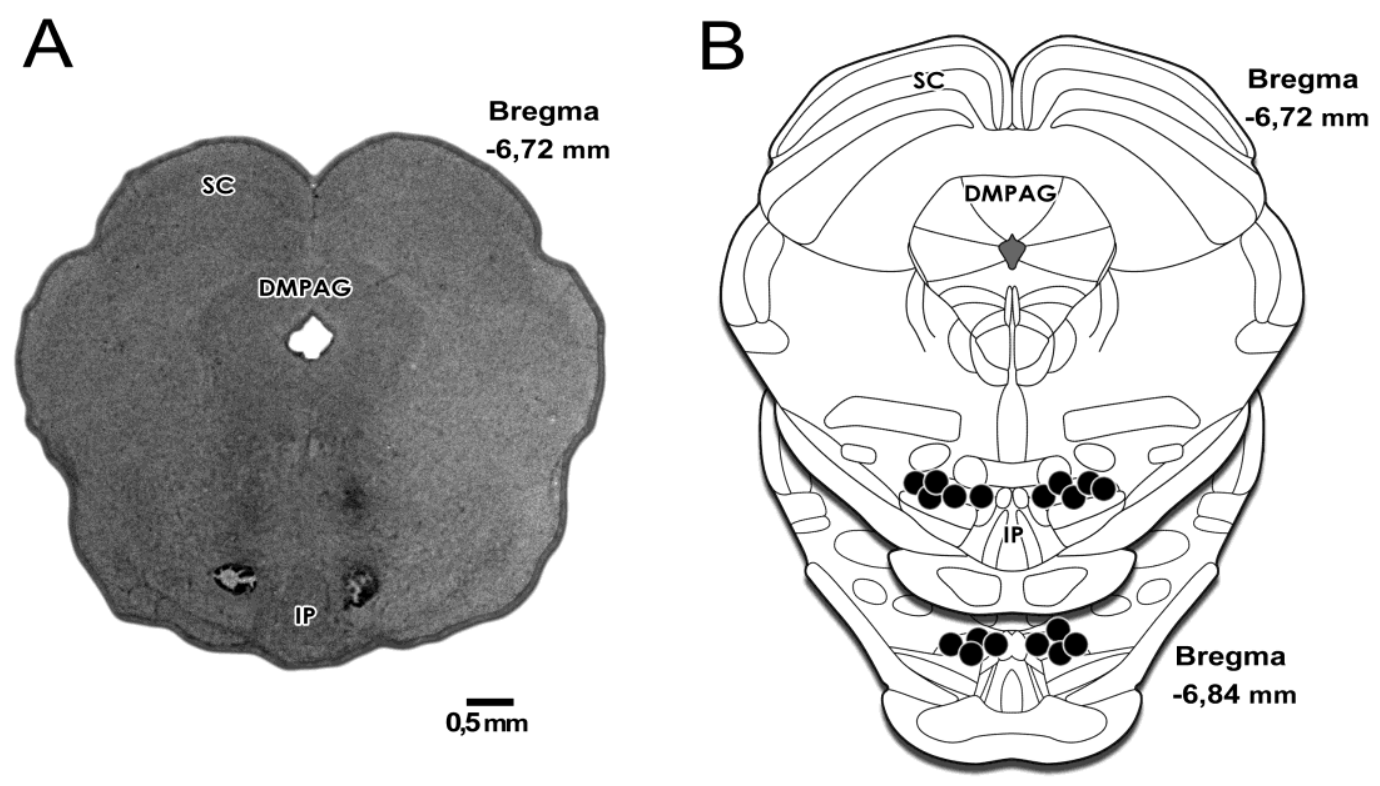

Fig. 10. Fotomicrografia com sítios representativos da localização das cânulas-guia na área tegmental ventral - ATV (A) e os sítios de microinjeção em diagramas de secções de mesencéfalo de ratos de acordo com o atlas de Paxinos e Watson (2007) (B). O número de pontos indicados é menor que o número de animais utilizados devido a sobreposições de sítios de microinjeção. Barra =0,5 mm. DMPAG $=$ Substância cinzenta periaquedutal dorsomedial; SC = Colículo superior; IP = Núcleo interpeduncular.

Na figura 11 podem ser observados os efeitos da microinjeção do agonista D2 quimpirole na ATV antes da sessão teste sobre a expressão do congelamento condicionado contextual dos animais. A ANOVA de uma via revelou diferenças significativas entre os grupos $[\mathrm{F}(2,28)=$ 4,64; $\mathrm{p}<0,05]$. O teste post hoc de Newman-Keuls revelou que o quimpirole foi eficaz em reduzir o tempo médio de congelamento dos animais em relação ao grupo controle (salina) e ao grupo que recebeu quimpirole em sítios fora da ATV $(p<0,05)$. Neste grupo, as agulhas de injeção foram localizadas fora da área tegmental ventral. 


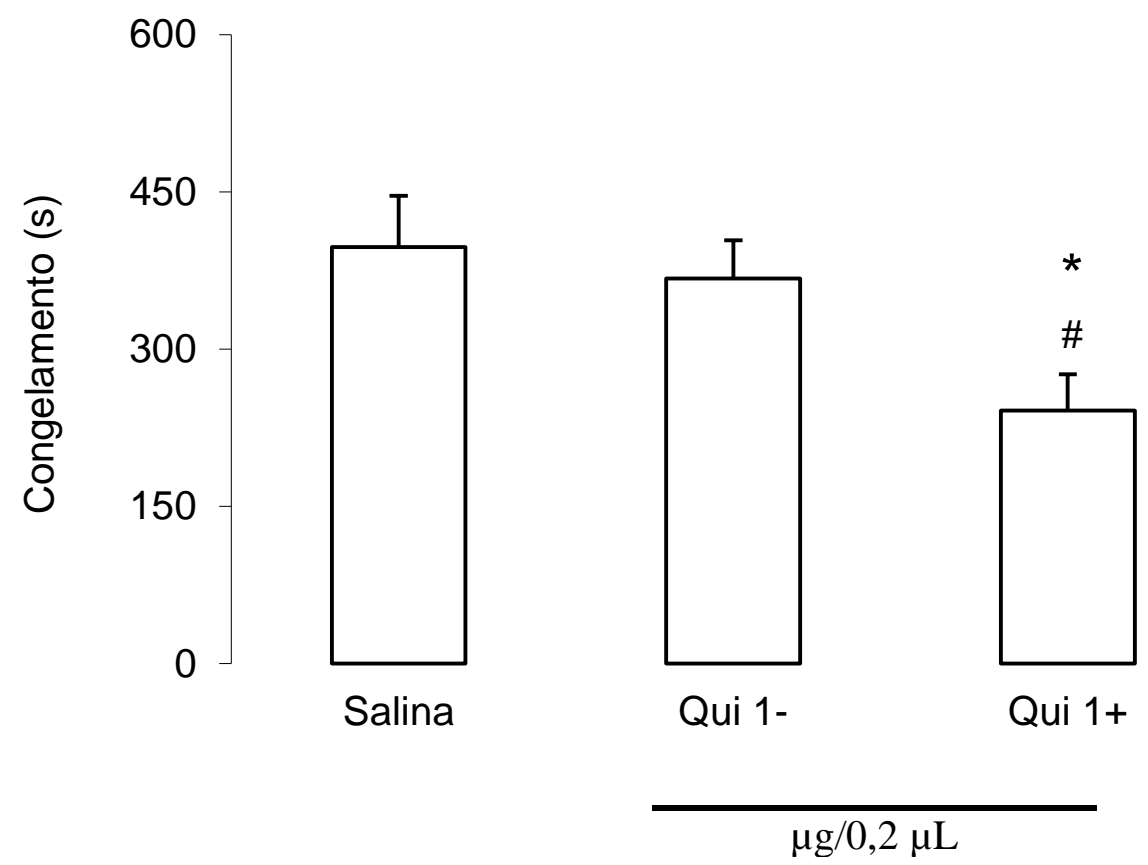

Fig. 11. Efeitos da microinjeção bilateral de salina ou quimpirole $1 \mu \mathrm{g}$ (Qui 1+) na área tegmental ventral antes da sessão teste sobre o tempo médio de congelamento de animais, avaliado na mesma sessão. Média + EPM. ${ }^{*} p<$ 0,05: diferente do grupo Salina; \# $p<0,05$ : diferente do grupo Qui 1- (grupo que recebeu quimpirole, mas que, entretanto, as agulhas de injeção não atingiram a ATV). $n=9$ para Salina; $n$ $=10$ para Qui 1-; e $n=12$ para Qui $1+$. 
Discussão 


\section{DISCUSSÃO}

Nos últimos anos tem se observado um aumento expressivo do número de pesquisas sobre as alterações na neurotransmissão dopaminérgica que ocorrem associadas à exposição do organismo a condições aversivas, como a estimulação de estruturas pertencentes ao sistema encefálico aversivo ou a exposição a estímulos aversivos condicionados. Diversos trabalhos mostram um aumento da liberação de dopamina em estruturas pertencentes ao sistema mesocorticolímbico, como o CPF, a amígdala e o núcleo accumbens, após estimulação aversiva (CUADRA et al., 2000; FEENSTRA et al., 1995). Vários estudos têm também mostrado que estímulos condicionados de medo promovem ativação do sistema dopaminérgico mesocorticolímbico (DE OLIVEIRA et al., 2011; INOUE et al., 2000; RUIZ-MARTINEZ et al., 2008). Tais achados indicam que a ativação desse sistema pode ser necessária para o estabelecimento de uma aprendizagem aversiva e/ou a posterior recuperação dessa informação. Desta forma, o presente estudo objetivou avaliar o envolvimento da neurotransmissão dopaminérgica na expressão do medo condicionado contextual.

O primeiro experimento, realizado para a obtenção de um controle adicional das condições experimentais, mostrou que os nossos parâmetros experimentais foram adequados para o estabelecimento de um condicionamento aversivo ao contexto. Os animais submetidos à sessão teste na caixa onde anteriormente ocorreu a sessão de condicionamento apresentaram um tempo médio de congelamento significativamente maior do aquele apresentado pelos grupos sem choque e contexto diferente. Esses resultados estão de acordo com os dados obtidos em estudo pioneiro de Bolles \& Collier (1976), que demonstraram que respostas emocionais de medo podem ser aprendidas a partir da associação de estímulos presentes no contexto do animal com um estímulo incondicionado aversivo, como choques nas patas.

No segundo experimento foi avaliado o envolvimento dos receptores D1 e D2 na expressão do medo condicionado ao contexto. Não foram observadas alterações na expressão do congelamento condicionado contextual com a utilização dos fármacos que atuam em receptores 
da família D1, SCH 23390 e SKF 38393. Esses resultados estão de acordo com outros relatos presentes na literatura que apontam que estes receptores podem não estar envolvidos na expressão do medo condicionado (DE OLIVEIRA et al., 2006, DE OLIVEIRA et al., 2009; INOUE ET al., 2000). As doses de 0,025 e 0,05 mg/Kg de SCH 23390 e as doses utilizadas de SKF 38393 não afetaram a atividade motora dos animais. Já a dose de 0,1 mg/Kg de SCH 23390 promoveu um déficit motor no teste do campo aberto; entretanto, não alterou o congelamento condicionado ao contexto. Esse dado constitui-se em evidência adicional que corrobora com a idéia de que os receptores D1 podem não estar envolvidos na expressão do medo condicionado.

Já com relação aos receptores D2, os dados obtidos com a administração sistêmica de quimpirole (agonista D2) confirmam o envolvimento da neurotransmissão dopaminérgica na expressão do medo condicionado, haja vista que as duas doses de quimpirole utilizadas $(0,1$ e 0,25 mg/Kg) diminuíram de forma dose-dependente a expressão do congelamento condicionado ao contexto. Dados similares foram obtidos no trabalho de De Oliveira e colaboradores (2006) que observaram a diminuição do sobressalto potencializado pelo medo com a administração sistêmica da mesma droga e utilizando, entretanto, a luz como estímulo condicionado.

A administração periférica do antagonista de receptores D2 sulpirida (dose de $40 \mathrm{mg} / \mathrm{Kg}$ ) também alterou a expressão do medo condicionado, observado através da diminuição do congelamento condicionado contextual. Esse resultado corrobora os dados presentes na literatura que indicam que a utilização dessa droga leva a uma diminuição do medo condicionado (BOSCHEN et al., 2009, CARVALHO et al., 2009; REIS et al., 2004). Assim, os dados obtidos neste estudo com a utilização de um agonista e de um antagonista de receptores D2 confirmam a participação de tais receptores na expressão do medo condicionado contextual.

Efeitos similares - a diminuição da expressão da resposta emocional condicionada observados tanto com a administração de um agonista quanto de um antagonista, parecem incongruentes, haja vista que seria esperado que a ativação e o bloqueio de um mesmo tipo de receptor produzissem efeitos opostos. Entretanto, deve ser ressaltado que os receptores 
dopaminérgicos D2 podem ser encontrados tanto pré quanto pós-sinapticamente, sendo que os autoreceptores atuam na regulação da liberação de dopamina e são encontrados, em sua maioria, nos corpos celulares e dendritos de neurônios dopaminérgicos da ATV e substância negra. Sabese que esses receptores são mais sensíveis do que os pós-sinápticos à ação de drogas dopaminérgicas, sendo, portanto, mais facilmente ativados em menores concentrações do fármaco (SKIRBOLL et al., 1979). Assim, os efeitos de quimpirole e sulpirida obtidos no experimento II podem ter ocorrido devido a uma ação distinta em receptores pré e póssinápticos, respectivamente. Esta hipótese foi testada no Experimento III, com a administração intra-ATV de quimpirole.

Como a dopamina é um importante neurotransmissor também envolvido com a atividade motora devido a sua ação no sistema nigroestriatal, poder-se-ia argumentar que os resultados obtidos com a utilização das drogas dopaminérgicas que atuam em receptores da família D2 ocorreram devido a uma ação na motricidade dos animais, não se relacionando, portanto, a uma alteração no sistema emocional de medo. Evidências contrárias a essa hipótese advêm dos resultados obtidos no teste do campo aberto, cujas análises estatísticas mostraram que a atividade motora dos ratos não foi alterada pela utilização de quimpirole e sulpirida. Além disso, as doses utilizadas no presente trabalho foram escolhidas partindo do pressuposto de que as mesmas não afetariam a atividade motora dos animais, com base em estudos deste e de outros laboratórios (CARVALHO et al., 2009; DE OLIVEIRA et al., 2006; REIS et al., 2004; STUCHLIK et al., 2007).

No experimento III foi avaliado o envolvimento dos receptores D2 da ATV na expressão do medo condicionado contextual. A microinjeção bilateral de quimpirole nesta estrutura levou a uma diminuição da expressão do medo condicionado, uma vez que houve uma redução significativa do congelamento em relação ao grupo salina. A especificidade da ATV como sítio de ação do quimpirole é atestada pelo fato de que os animais que receberam essa droga fora da ATV apresentaram um tempo de congelamento similar aquele do grupo salina, e maior do que o 
congelamento dos animais tratados com quimpirole na ATV. Estes dados corroboram inúmeros estudos presentes na literatura que mostram que a injeção intra-ATV deste agonista D2 promove a ativação de autoreceptores dessa estrutura e diminui a expressão do medo condicionado, provavelmente através da diminuição da liberação de dopamina em estruturas que recebem projeções da área tegmental ventral (DE OLIVEIRA et. al, 2009; MUNRO \& KOKKINIDIS, 1997; NADER \& LEDOUX, 1999). Tal hipótese é confirmada com dados da literatura que demonstram que ocorre uma diminuição dos níveis de dopamina na amígdala basolateral e do congelamento condicionado à luz com a injeção pré-teste de quimpirole na ATV (DE OLIVEIRA et al., 2011).

Assim, pode-se hipotetizar que os estímulos que adquirem saliência e conotação aversiva devido a aprendizagem associativa ocorrida no condicionamento, ao atingirem a ATV levam a uma intensificação da atividade dopaminérgica no sistema mesocorticolímbico. A ativação desse sistema levaria a um conjunto de respostas cognitivas e comportamentais que são adaptativas para o organismo face às alterações do meio em que vive. Tal intensificação dopaminérgica observada na presença de estímulos aversivos condicionados levaria assim à expressão de respostas emocionais, juntamente com um aumento da atenção e alerta, à recuperação de memórias aversivas e à seleção de respostas para enfrentar o estímulo estressor. Logo, seria esperado que a diminuição de dopamina em estruturas do circuito mesocorticolímbico, através do antagonismo de receptores dopaminérgicos, levasse a uma diminuição do medo condicionado. Essa hipótese foi confirmada por estudos que observaram a diminuição do medo condicionado com a infusão de antagonistas D2 em estruturas como amígdala e núcleo accumbens (BOSCHEN et al., 2011; DE OLIVEIRA et al., 2011; GUARRACI et al., 2000). É possível que a diminuição da neurotransmissão dopaminérgica no sistema mesocorticolímbico atenue a saliência e as propriedades excitatórias adquiridas pelo estímulo condicionado, gerando, a nível emocional, uma resposta de medo menos intensa do animal ao contato com o estímulo aversivo. 
Logo, a capacidade do quimpirole e sulpirida em reduzir a expressão do congelamento condicionado ao contexto, obtida no presente estudo com a administração sistêmica de tais drogas, provavelmente ocorreu devido a uma ação em receptores pré-sinápticos da ATV e em receptores pós-sinápticos de estruturas do sistema mesocorticolímbico que recebem projeções da área tegmental ventral, respectivamente. A diminuição do medo condicionado contextual observada com a infusão de quimpirole na ATV confirma esta hipótese, demonstrando que a ativação dos autoreceptores D2 de tal estrutura, possivelmente levou a uma diminuição da liberação de dopamina para estruturas como amígdala, núcleo accumbens e CPF.

Os resultados desse estudo sugerem, portanto, que a intensificação da neurotransmissão dopaminérgica não ocorre somente nos estados motivacionais relacionados à recompensa, mas que está envolvida, também, na neurotransmissão dos estados aversivos. A liberação de dopamina para as diferentes estruturas do sistema mesocorticolímbico poderia atuar na modulação das respostas de medo. O aumento da transmissão dopaminérgica no CPF, por exemplo, poderia refletir a intensificação da atenção, alerta e de outros processos cognitivos para a elaboração de estratégias de enfrentamento eficazes contra o estímulo aversivo. Já o aumento de dopamina na amígdala poderia estar relacionado com a expressão da resposta emocional de medo; e a intensificação dopaminérgica no núcleo accumbens poderia estar relacionada com o sistema motivacional de medo, levando o animal a se engajar em comportamentos que visem terminar ou evitar a estimulação aversiva.

A dopamina é um dos principais neurotransmissores do sistema nervoso central, atuando em diversas funções que são vitais para os animais, como a motricidade, através principalmente do sistema nigroestriatal; o sistema de recompensas, através do feixe prosencefálico medial; e a aprendizagem e funções cognitivas, através de áreas prosencefálicas, como o CPF. Assim, a utilização da dopamina como um marcador bioquímico de um estado emocional de medo ou ansiedade deve ser feita com cautela, haja vista as inúmeras funções modulatórias deste 
neurotransmissor e o fato de a intensificação dopaminérgica que ocorre nos estados aversivos pode não refletir somente um estado emocional (D’ANGIO ET AL., 1988).

Em suma, esse estudo aponta para a participação de mecanismos mediados por receptores D2 na expressão do medo condicionado contextual, além de mostrar que uma via dopaminérgica mesolímbica originária da área tegmental ventral participa desse processo. Entretanto, estudos ainda devem ser realizados para melhor caracterizar a mediação dopaminérgica em estados emocionais aversivos. Isto implica em entender, por exemplo, se tal intensificação contribui para um processamento seletivo da informação e aumento da atenção e alerta, fazendo o sujeito perceber a existência de estímulos aversivos em seu ambiente; procurar compreender se os mecanismos dopaminérgicos nos estados de medo e ansiedade têm também a função de levar o indivíduo a buscar estratégias eficazes para lidar com o estímulo estressor; ou ainda, estudar se essa neurotransmissão dopaminérgica tem a função de motivar o organismo a fugir ou esquivar-se do evento aversivo. Além disso, a relação entre a intensificação dopaminérgica que ocorre nos estados emocionais de medo e ansiedade e outros sistemas neurofisiológicos, como a ativação do eixo hipotálamo-hipófise-adrenal, sistemas hormonais, entre outros, deve também ser investigada. 
Conclusões 


\section{CONCLUSÕES}

- Mecanismos dopaminérgicos estão envolvidos na mediação de estados emocionais de medo e ansiedade induzidos por estímulos condicionados aversivos.

- Receptores da família D2, mas não D1, parecem estar envolvidos na expressão do medo condicionado contextual, uma vez que a administração sistêmica de quimpirole (agonista D2) e sulpirida (antagonista D2), mas não de SKF 38393 (agonista D1) e SCH 23390 (antagonista D1), promoveu uma diminuição no congelamento condicionado ao contexto.

- A diminuição do medo condicionado ao contexto causada pelo quimpirole deve-se à sua ação em autoreceptores D2 da área tegmental ventral e, possivelmente, à conseqüente diminuição da liberação de dopamina em áreas límbicas como amígdala, núcleo accumbens e córtex pré-frontal. Já a sulpirida deve agir nessas regiões em receptores pós-sinápticos. 
Referências Bibliográficas 


\section{REFERÊNCIAS BIBLIOGRÁFICAS}

ABERCROMBIE, E. D.; KEEFE, K. A.; DIFRISCHIA, D. S.; ZIGMOND, M. J. Differential effect of stress on in vivo dopamine release in striatum, nucleus accumbens, and medial frontal cortex. Journal of Neurochemistry, v. 52, p. 1655-1658, 1989.

BLANCHARD, R. J.; BLANCHARD, D. C. Defensive reactions of laboratory and wild Rattus Norvegicus. Journal Comparative Psychology, v. 100, p. 101-107, 1986.

BOLlES, R. C.; COLliER, A. C. The effect of predictive cues on freezing in rats. Animal Learning and Behavior, v. 4, p. 6-8, 1976.

BORELLI, K. G.; NOBRE, M. J.; BRANDÃO, M. L.; COIMBRA, N. C. Effects of acute and chronic fluoxetine and diazepam on freezing behavior induced by electrical stimulation of dorsolateral and lateral columns of the periaqueductal gray matter. Pharmacology, Biochemistry and Behavior, v. 77, p. 557-566, 2004.

BOSCHEN, S. L.; WIETZIKOSKI, E. C.; WINN, P.; CUNHA, C. da. The role of nucleus accumbens and dorsolateral striatal D2 receptors in active avoidance conditioning. Neurobiology of Learning and Memory, v. 96, p. 254-262, 2011.

BRANDÃO, M. L.; TRONCOSO, A. C.; SILVA, M. A. S.; HUSTON, J. P. The relevance of neuronal substrates of defense in the midbrain tectum to anxiety and stress: empirical and conceptual considerations. European Journal of Pharmacology, v. 463, p. 225-233, 2003.

BRANDÃO, M. L. Comportamento Emocional. In: BRANDÃO, M.L. As bases biológicas do comportamento: introdução à neurociência. São Paulo: EPU, 2004. Cap.7, p. 117-140.

BRANDÃO, M. L.; ZANOVELI, J. M.; RUIZ-MARTINEZ, R. C.; OLIVEIRA, L. C.; LANDEIRA-FERNANDEZ, J. Different patterns of freezing behavior organized in the periaqueductal Gray of rats: Association with different types of anxiety. Behavioural Brain Research, v. 188, p. 1-13, 2008. 
BRISCHOUX, F.; CHAKRABORTY, S.; BRIERLEY, D. I.; UNGLESS, M. A. Phasic excitation of dopamine neurons in ventral VTA by noxious stimuli. PNAS, v. 106, p. 4894-4899, 2009.

CALLIER, S.; SNAPYAN, M.; CROM, S.; PROU, D.; VICENT, J.; VERNIER, P. Evolution and cell biology of dopamine receptors in vertebrates. Biology of the Cell, v. 95, p. 489-502, 2003.

CARVAlHO, J. D. M.; DE OlIVEIRA, A. R.; SilvA, C. B.; BRANDÃO, M. L. A comparative study on the effects of the benzodiazepine midazolam and the dopamine agents, apomorphine and sulpiride, on rat behavior in the two-way avoidance test. Pharmacology, Biochemistry and Behavior, v. 92, p. 351-356, 2009.

CUADRA, G.; ZURITA, A.; MACEDO, C. E.; MOLINA, V. A.; BRANDÃO, M. L. Electrical stimulation of the midbrain tectum enhances dopamine release in the frontal cortex. Brain Research, v. 52, p. 413-418, 2000.

D’ANGIO, M.; SERRANO, A.; DRISCOLL, P.; SCATTON, B.; Stressful environmental stimuli increase extracellular DOPAC levels in the prefrontal cortex of hypoemotional (Roman highavoidance) but not hyperemotional (Roman low-avoidance) rats. An in vivo voltammetric study. Brain Research, v. 451, p. 237-247, 1988.

DARWIN, C. The expression of the emotions in man and animals. $1^{\text {st }}$. Edition. London: John Murray, 1872.

DE OLIVEIRA, A. R.; REIMER, A. E.; BRANDÃO, M. L. Dopamine D2 receptor mechanisms in the expression of conditioned fear. Pharmacology, Biochemistry and Behavior, v. 84, p. 102-111, 2006.

DE OLIVEIRA, A. R.; REIMER, A. E.; BRANDÃO, M. L. Role of dopamine receptors in the ventral tegmental area in conditioned fear. Behavioural Brain Research, v.199, p. 271-277, 2009. 
DE OLIVEIRA, A. R.; REIMER, A. E.; MACEDO, C. E.; CARVALHO, M. C.; SILVA, M. A.; BRANDÃO, M. L. Conditioned fear is modulated by D2 receptor pathway connecting the ventral tegmental area and basolateral amygdala. Neurobiology of Learning and Memory, v. 95, p. 37-45, 2011.

FENDT, M.; FANSELOW, M. S. The neuroanatomical and neurochemical basis of conditioned fear. Neuroscience and Biobehavioral Reviews, v. 23, p. 743-760, 1999.

FEEnstra, M. G. P; BOTTERBlom, M. H. A.; VAN UUM, J. F. M. Novelty-induced increase in dopamine release in the rat prefrontal córtex in vivo: inhibition by diazepam. Neuroscience Letters, v. 189, p. 81-84, 1995.

GARCIA, A. M. B.; MARTINEZ, R.; BRANDÃO, M. L.; MORATO, S. Effects of apomorphine on rat behavior in the elevated plus-maze. Physiology $\&$ Behavior, v. 85, p. 440447, 2005.

GRAEFF, F. G. Minor tranquilizers and brain defense systems. Brazilian Jounal of Medical and Biological Research, v. 14, p. 239-265, 1981.

GRAEFF, F. G. Neuroanatomy and neurotransmitter regulation of defensive behaviors and related emotions in mammals. Brazilian Jounal of Medical and Biological Research, v. 27, p. 811-824, 1994.

GRAY, J. A.; MCNAUGHTON, N. The neuropsychology of anxiety: na equiry on the functions of the septo-hippocampal system. Oxford: Oxford University Press, 2000.

GROSS, C.; HEN, R. The developmental origins of anxiety. Nature Rewiews, v. 5, p. 545-552, 2004.

GUARRACI, F. A.; KAPP, B. S. An electrophysiological characterization of ventral tegmental area dopamine neurons during differential pavlovian fear conditioning in the awake rabbit. Behavioral Brain Research, v. 99, p. 169-179, 1999. 
GUARRACI, F. A.; FROHARDT, R. J.; FALLS, W. A.; KAPP, K. S. The effects of intraamygdaloid infusion of a D2 dopamine receptor antagonist on Pavlovian fear conditioning. Behavioural Neuroscience, v. 114, p. 647-651, 2000.

INDOVINA, I.; ROBBINS, T. W.; NÚÑEZ-ELIZALDE, A. O.; DUNN, B. D.; BISHOP, S. J. Fear-Conditioning mechanisms associated with vulnerability to anxiety in humans. Neuron, v. 69, p. 563-571, 2011.

INOUE, T.; IZUMI, T.; MAKI, Y.; MURAKI, I.; KOYAMA, T. Effect of the dopamine D1/5 antagonist SCH 23390 on the acquisition of conditioned fear. Pharmacology Biochemistry and Behavior, v. 66, p. 573-578, 2000.

KINDT, M.; SOETER, M.; VERVLIET, B. Beyond extinction: erasing human fear responses and preventing the return of fear. Nature Neuroscience, v. 12, p. 256-258, 2009.

LEDOUX, J. Alguns graus de distância. In: LEDOUX, J. O cérebro emocional: os misteriosos alicerces da vida emocional. Rio de Janeiro: Objetiva, 2001. Cap. 6, p. 126-163.

MISSLIN, R., The defense system of fear: behavior and neurocircuitry. Neurophysiologie Clinique, v. 33, p. 55-66, 2003.

MONSMA, F. J.; MAHAN, L. C.; MCVITTIE, L. D.; GERFEN, C. R.; SIBLEY, D. R. Molecular cloning and expression of a D1 dopamine receptor linked to adenyl cyclase activation. Procedings of the National Academy of Sciences of the United States of America, v. 87, p. 6723-6727, 1990.

MOORE, R. Y.; BLOOM, F. E. Central catecholamine neuron systems: Anatomy and Physiology of the dopamine systems. Annual Reviews Neuroscience, v. 1, p. 129-169, 1978.

MUNRO, L. J.; KOKKINIDIS, L. Infusion of quinpirole and muscimol into the ventral tegmental area inhibits fear-potentiated startle: implications for the role of dopamine in fear expression. Brain Research, v. 746, p. 231-238, 1997. 
NADER, K.; LEDOUX, J. E. Inhibition of the mesoamygdala dopaminergic pathway impairs the retrieval of conditioned fear associations. Behavioural Neuroscience, v. 113, p. 891-901, 1999.

OADES, R. D.; HALLIDAY, G. M. Ventral tegmental (A10) system: neurobiology. 1.Annatomy and connectivy. Brain Research, v. 434, p. 117-165, 1987.

OLDS, J.; MILNER, P. Positive reinforcement produced by electrical stimulation of septal area and other regions of rat brain. Journal of Comparative and Physiological Psycology, v. 47, p. 419-427, 1954.

PANI, L.; PORCELLA, A.; GESSA, G. L. The role of stress in the pathophysiology of the dopaminergic system. Molecular Psychiatry, v. 5, p. 14-21, 2000.

PAXINOS, G.; WATSON, C. The rat brain in stereotaxic coordinates. $5^{\text {th }}$ Edition. San Diego: Academic Press, 2007.

REIS, F. L. V.; MASSON, S.; DE OLIVEIRA, A. R.; BRANDÃO, M. L. Dopaminergic mechanisms in the conditioned and unconditioned fear as assessed by the two-way avoidance and light switch-off tests. Pharmacology, Biochemistry and Behavior, v. 79, p. 359-365, 2004.

RUIZ-MARTINEZ, R. C.; DE OLIVEIRA, A. R.; BRANDÃO, M. L. Conditioned and unconditioned fear organized in the periaqueductal gray are differentially sensitive to injections of muscimol into amygdaloid nuclei. Neurobiology of Learning and Memory, v. 85, p. 58-65, 2006.

RUIZ-MARTINEZ, R. C.; DE OLIVEIRA, A. R.; BRANDÃO, M. L. Serotoninergic mechanisms in the basolateral amygdala differentially regulate the conditioned and unconditioned fear organized in the periaqueductal gray. European Neuropsychopharmacology, v. 17, p. 717-724, 2007.

RUIZ-MARTINEZ, R. C.; DE OLIVEIRA, A. R.; MACEDO, C. E., BRANDÃO, M. L. Involvement of dopaminergic mechanisms in the nucleus accumbens core and shell subregions in the expression of fear conditioning. Neuroscience Letters, v. 446, p. 112-116, 2008. 
SALUM, C.; GUIMARÃES, F. S.; BRANDÃO, M. L.; DEL BEL, E.A. Dopamine and nitric oxide interaction on the modulation of prepulse inhibition of the acoustic startle response in the Wistar rat. Psychopharmacology, v. 185, p. 133-141, 2006.

SANTOS, J. M.; GÁRGARO, A.C.; DE OLIVEIRA, A. R.; MASSON, S.; BRANDÃO, M. L. Pharmacological dissociation of moderate and high fear as assessed by freezing behavior and fear-potentiated startle. European Neuropsychopharmacology, v. 15, p. 239-246, 2005.

SILVEIRA, M. C. L.; ZANGROSSI, H.; VIANA, M. B.; SILVEIRA, R.; GRAEFF, F. G. Differential expression of Fos protein in the rat brain induced by performance of avoidance or scape in the elevated T-maze. Behavioral Brain Research, v. 126, p. 13-21, 2001.

SKIRBOLL, L. R.; GRACE, A. A.; BUNNEY, B. S. Dopamine Auto - and Postsynaptic Receptors: Electrophysiological Evidence for Differential Sensitivity to Dopamine Agonists. Science, v. 206, p. 80-82, 1979.

STUCHLIK, A.; REHAKOVA, L.; RAMBOUSEK, L.; SVOBODA, J.; VALES, K. Manipulation of D2 receptors with quinpirole and sulpiride affects locomotor activity before spatial behavior of rats in na active place avoidance task. Neuroscience Research, v. 58, p. 133$139,2007$.

ZANOVELI, J. M.; BRANDÃO, M. L. The dorsal periaqueductal and basolateral amygdala are necessary for the expression of conditioned place avoidance induced by semicarbazide stimulation of the dorsal periaqueductal region. Progress in Neuropsychopharmacology \&. Biological Psychiatry, v. 32, p. 1715-1721, 2008.

ZANOVELI, J. M.; CARVALHO, M. C.; CUNHA J. M.; BRANDÃO, M. L. Extracelular serotonin level in the basolateral nucleus of the amygdale and dorsal periaqueductal gray under unconditioned and conditioned fear states: An in vivo microdialysis study. Brain Research, v. 1294, p. 106-115, 2009. 